\title{
Discovery of Novel Caeridins from the Skin Secretion of the Australian White's Tree Frog, Litoria caerulea
}

\author{
Lei Li $\mathbb{D}^{1},{ }^{1}$ Qing Wu, ${ }^{2}$ Xi Wang, ${ }^{1}$ Huimin Lu, ${ }^{1}$ Xinping Xi $\mathbb{D},{ }^{1}$ Mei Zhou ${ }^{1},{ }^{1}$ Chris J. Watson, ${ }^{3}$ \\ Tianbao Chen ${ }^{(D)}{ }^{1}$ and Lei Wang $\mathbb{D}^{1}$ \\ ${ }^{1}$ Natural Drug Discovery Group, School of Pharmacy, Queen's University, Belfast BT9 7BL, UK \\ ${ }^{2}$ School of Chinese Materia Medica, Beijing University of Chinese Medicine, Beijing 102488, China \\ ${ }^{3}$ Centre for Experimental Medicine, School of Medicine, Dentistry and Biomedical Sciences, Queen's University, Belfast BT9 7BL, UK
}

Correspondence should be addressed to Lei Li; lei.li@qub.ac.uk and Mei Zhou; m.zhou@qub.ac.uk

Received 23 January 2018; Revised 25 April 2018; Accepted 10 May 2018; Published 11 July 2018

Academic Editor: Marco Gerdol

Copyright (c) 2018 Lei Li et al. This is an open access article distributed under the Creative Commons Attribution License, which permits unrestricted use, distribution, and reproduction in any medium, provided the original work is properly cited.

\begin{abstract}
Abundant biologically active peptides have been discovered from frog skin secretions, a rich natural source of bioactive compounds with great potential in drug discovery. In this study, three Caeridin peptides, namely, Caeridin-1, S5-Caeridin-1, and Caeridin-a1, were discovered from the skin secretion of the Australian White's tree frog, Litoria caerulea, for the first time, by means of combining transcriptomic and peptidomic analyses. It also represents the first report on bioactive Caeridins since this family of peptides was initially studied 20 years ago. Chemically synthetic versions of each natural Caeridin demonstrated promising bioactivities either on rat smooth muscles or against microbial growth. Specifically, Caeridin-1 produced contraction of rat bladder smooth muscle, while S5-Caeridin-1 induced relaxation of rat ileum smooth muscle, both at nanomolar concentrations. Moreover, Caeridin-al was shown to potently inhibit the growth of the planktonic Gram-positive bacteria Staphylococcus aureus (S. aureus), methicillin-resistant S. aureus (MRSA), and Enterococcus faecalis (E. faecalis), the Gram-negative bacterium, Escherichia coli (E. coli), and the yeast, Candida albicans (C. albicans). The discovery of these Caeridins may induce further intensive and systematic studies of frog skin peptides to promote the discovery of natural templates as lead compounds for drug discovery and therapeutic application.
\end{abstract}

\section{Introduction}

In recent years, peptide and peptide-based drugs have been developing fast and have pioneered an essential area in the pharmaceutical industry [1]. Peptide-based medicinal therapy could offer benefits over other biologics, while demanding less costs in production [1]. Recent trends suggest that the application of therapeutic peptides is becoming more popular, and it has extended to the treatment of many diseases, such as infection, cancer, enzyme deficiency disorders, protein-dysfunction disorders, and even genetic and degenerative diseases [2].

Frog skin with poisonous glands can produce secretions in a holocrine manner and release complex chemical contents [3-5]. On the one hand, peptides and proteins contained in these secretions have been considered to play different but important roles in regulating frogs' physiological functions and defense against predators and microorganisms. On the other hand, they have been proven to hold hidden treasures to supplement drug development [6]. However, with the observed global decline in the frog population during the 1980s, including species extinction, it became apparent that this potentially valuable natural resource needed environmental protection and animal conservation to ensure peptide discovery and acquisition from these natural products could continue and play a role in the future development of novel therapeutic peptides $[7,8]$.

The Australian White's tree frog, Litoria caerulea (L. caerulea), belongs to the tree frog family Hylidae. Most members of this tree frog family can produce multiple defensive and regulatory chemical compounds in their skin secretions to provide protective survival advantages in their natural environment. Compared with the peptide discovery research on other tree frogs, previous studies on the skin 
secretions of L. caerulea were not as productive in terms of peptide quantities acquired and in the limited identification of peptides with a range of bioactive properties. The original study investigating peptides derived from L. caerulea was conducted in 1993 by Waugh et al. [9] who reported the discovery of 25 peptides from the secretions of the parotoid glands, including Caerulein 1, eighteen Caerins, and six Caeridins (Caeridins 1-6), the latter also being evidenced later in four other Australian frog species, including, L. gilleni, L. splendida, L. xanthomera, and L. chloris. In 1997, Steinborner et al. [10] reported the discovery of Caeridin 7.1 from the dorsal glandular skin extract of the brown tree frog, Litoria ewingii. Interestingly, with the Caeruleins showing hypotensive bioactivity and the Caerins antimicrobial activity, the Caeridins, however, were not reported to display any structural and functional resemblance to the Caerulein and Caerin peptides. These small Caeridin peptides (about 1000$1500 \mathrm{Da})$, comprising of $12-15$ amino acid residues, share the same sequence -Gly-Leu-Leu/Phe- at the N-terminal ends and -Leu/Ile $\left(\mathrm{NH}_{2}\right)$ at the C-terminal ends. Each of this Caeridins may be well fitted into an $\alpha$-helical wheel with clearly delineated hydrophilic and hydrophobic zones [9]. The possession of dominant hydrophobic zones may suggest appreciable hydrophobic moments of these Caeridins and consequentially may bind more easily to the surface of biological membranes [11]. However, despite their distinct structural features, none of the Caeridins was reported to have any bioactive functions within these previous studies, which might explain why there has been no research reported on Caeridins over the last 20 years. Here, we report the isolation and structural characterisation of Caeridin-1 and two novel Caeridins from the skin secretion of $L$. caerulea, which were obtained through an ecofriendly method described previously [12], using parallel transcriptomic and peptidomic analyses, as well as through examining their biological activities using synthetic versions in a variety of bioassays.

\section{Results}

2.1. "Shotgun" Cloning of cDNAs Encoding Caeridins. Preprocaeridin cDNAs were consistently cloned from the skin secretion cDNA library, and each encoded a single copy of Caeridin, which were named Caeridin-1, S5-Caeridin-1, and Caeridin-a1 shown in Figure 1. The putative signal peptide sequences were localized to the acidic spacer peptide and were highly identical in structure. The latter encoding regions were flanked at the $\mathrm{N}$-terminus by classical propeptide convertase-processing sites involving a propeptide convertase with -Lys-Arg- (-KR-) cleavage specificity, which suggested that there were mutations in the structure. Alignments of the full-length nucleic acid sequences and the translated open-reading frame amino acid sequences are shown in Figure 2 and highlight that preprocaeridins exhibit high degrees of both nucleotide and peptide primary structural similarities and conservation. Transcripts of Caeridin-1, S5-Caeridin-1, and Caeridin-a1 were registered with and deposited at http://www.ebi.ac.uk/ena/data/view/ permanently under the accession numbers LT852758, LT852759, and LT853865, respectively. Caeridin-1, S5-Caeridin-1, and
Caeridin-al were compared with other Caeridins isolated from $L$. caeulea, and their amino acid sequences showed certain degrees of similarities suggested by the amino acid alignment in Figure 3.

\subsection{Fractionation and Primary Structural Identification of} Caeridins. The computed molecular masses of the deduced primary structures of Caeridin-1, S5-Caeridin-1, and Caeridin-al located within the open-reading frames of respective cloned cDNAs were used to detect each Caeridin within reversed-phase HPLC fractions as shown in Figure 4, which were subjected to mass spectrometric analysis. The primary structures of each Caeridin were confirmed by tandem mass spectrometric (MS/MS) fragmentation as shown in Figure 5 and Table 1. The existence of C-terminal amidation of each Caeridin was confirmed with the appropriated positioned $\mathrm{G}$ residue playing as the amide donor.

\subsection{Secondary Structural Identification and Physicochemical} Property Analysis of Caeridins. The purified synthetic replicates of Caeridins were subjected to secondary structural identification. From the CD spectra, these positive bands at $190 \mathrm{~nm}$ and double-negative bands at $208 \mathrm{~nm}$ and $222 \mathrm{~nm}$ in the $10 \mathrm{mM} \mathrm{NH}_{4} \mathrm{Ac}$ with $50 \%$ TFE solution indicated that Caeridin-1, S5-Caeridin-1, and Caeridin-a1 adopted a typical $\alpha$-helical secondary structure in a membrane mimic environment (Figure 6). Multiple CD analysis methods were used and processed by the K2D3 online portal to measure the $\alpha$ helicity of these Caeridins (Table 2) [13].

The newly discovered Caeridins together with the previously reported Caeridins were subjected to the analysis of physicochemical properties by the Heliquest Analysis online bioinformatic tool [14]. The hydrophobicity, hydrophobic moment (amphipathicity), net charge, and charged residues of these Caeridins were determined and are shown in Table 3.

2.4. Smooth Muscle Pharmacological Activities of Caeridins. The purified synthetic replicates of Caeridins were subjected to smooth muscle pharmacological activity tests. Caeridin-1 was found to induce contractions on rat bladder smooth muscle, and S5-Caeridin-1 was found to have relaxation effects on rat ileum smooth muscle, at various concentrations, as shown in Figure 7. The half effective concentration $\left(\mathrm{EC}_{50}\right)$ of Caeridin-1 inducing rat bladder smooth muscle contractions was $5.6 \mathrm{nM}\left(5.6 \times 10^{-9} \mathrm{M}\right)$, and $\mathrm{EC}_{50}$ of $\mathrm{S} 5$ Caeridin-1 causing rat ileum smooth muscle relaxations was $9.5 \mathrm{nM}\left(9.5 \times 10^{-9} \mathrm{M}\right)$. The maximum contraction effect of Caeridin-1 on bladder smooth muscle preparations was $0.3 \mathrm{~g}$ in tension change, and the maximum relaxant effect of S5-Caeridin-1 on ileum smooth muscle preparations was $0.2 \mathrm{~g}$ in tension change. Caeridin-a1 did not show any smooth muscle activities.

2.5. Antimicrobial Activities of Caeridins. The purified synthetic replicates of Caeridins were subjected to antimicrobial activity tests, with melittin and bradykinin as positive and negative controls, respectively. Melittin originally discovered from the venom of the honeybee (Apis mellifera) has potent antimicrobial activities. The inclusion of melittin as the positive peptide in the antimicrobial activity tests set a reference 


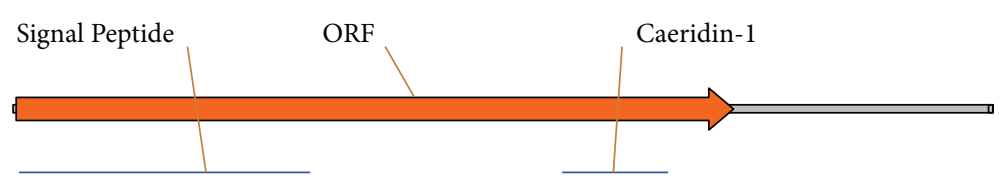

Caeridin-1

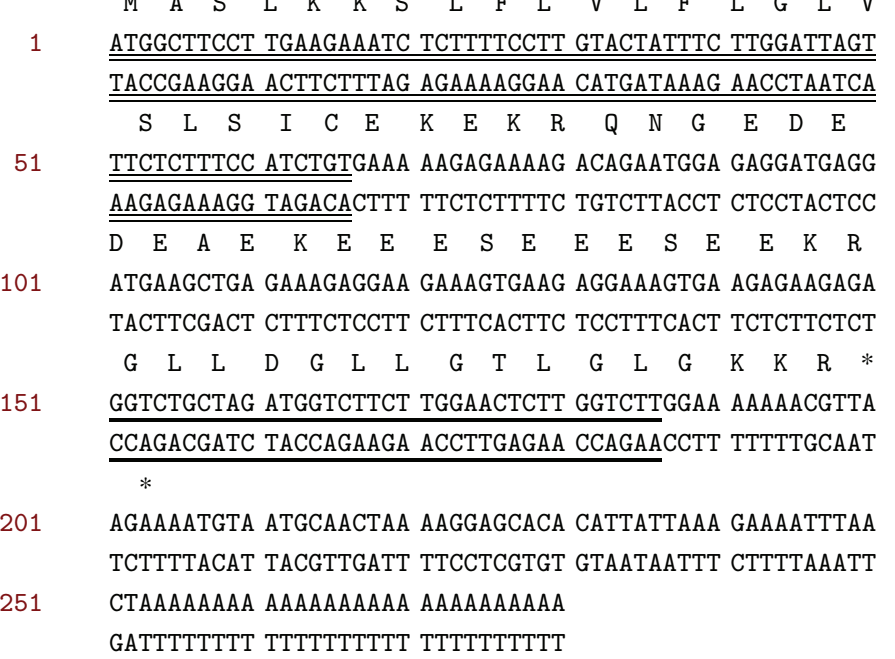

(a)

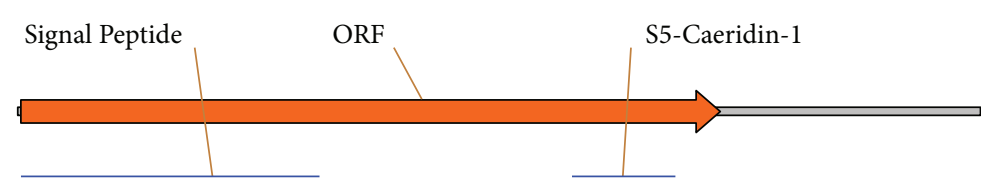

S5-Caeridin-1

\begin{tabular}{|c|c|}
\hline & S5-Caeridin-1 \\
\hline \multirow{4}{*}{1} & $\begin{array}{lllllllllllllllll}M & A & S & \text { L } & \text { K } & \text { K } & \text { S } & \text { L } & \text { F } & \text { L } & \text { V } & \text { L } & \text { F } & \text { L } & G & \text { L } & \text { V }\end{array}$ \\
\hline & ATGGCTTCCT TGAAGAAATC TCTTTTCCTT GTACTATTTC TTGGATTAGT \\
\hline & $\begin{array}{l}\text { TACCGAAGGA ACTTCTTTAG AGAAAAGGAA CATGATAAAG AACCTAATCA } \\
\end{array}$ \\
\hline & $\begin{array}{llllllllllllllll}S & L & S & I & C & E & K & E & K & R & Q & N & E & E & D & E\end{array}$ \\
\hline \multirow[t]{3}{*}{51} & TTCTCTTTCC ATCTGTGAAA AAGAGAAAAG ACAGAATGAA GAGGATGAGG \\
\hline & AAGAGAAAGG TAGACACTTT TTCTCTTTTC TGTCTTACTT CTCCTACTCC \\
\hline & $\begin{array}{llllllllllllllllll}\mathrm{D} & \mathrm{E} & \mathrm{A} & \mathrm{E} & \mathrm{K} & \mathrm{E} & \mathrm{E} & \mathrm{E} & \mathrm{S} & \mathrm{E} & \mathrm{E} & \mathrm{E} & \mathrm{S} & \mathrm{E} & \mathrm{E} & \mathrm{K} & \mathrm{R}\end{array}$ \\
\hline \multirow[t]{3}{*}{101} & ATGAAGCTGA GAAAGAGGAA GAAAGTGAAG AGGAAAGTGA AGAGAAGAGA \\
\hline & TACTTCGACT СTTTCTCCTT СTTTCACTTC TCCTTTCACT TCTCTTCTCT \\
\hline & 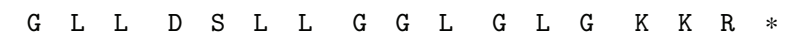 \\
\hline \multirow[t]{3}{*}{151} & GGTCTGCTAG ATAGTCTTCT TGGAGGTCTT GGTCTTGGAA AAAAACGTTA \\
\hline & $\overline{\text { CCAGACGATC TATCAGAAGA ACCTCCAGAA CCAGAACCTT TTTTTGCAAT }}$ \\
\hline & * \\
\hline \multirow[t]{2}{*}{201} & AGAAAATGTA ATGCAACTAA AAGGAGCACA CATTATTAAA GAAAATTTAA \\
\hline & TCTTTTACAT TACGTTGATT TTCCTCGTGT GTAATAATTT CTTTTAAATT \\
\hline \multirow[t]{2}{*}{251} & CTGAAAAAAA AAAAAAAAAA AAAAAAAAAA \\
\hline & GACTTTTTTT TTTTTTTTTT тTтTTTTTTT \\
\hline
\end{tabular}

(b)

Figure 1: Continued. 


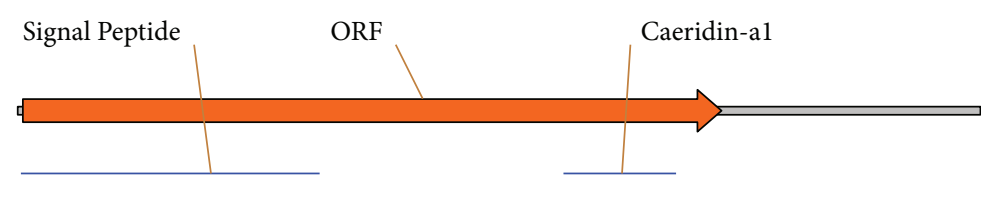

Caeridin-al

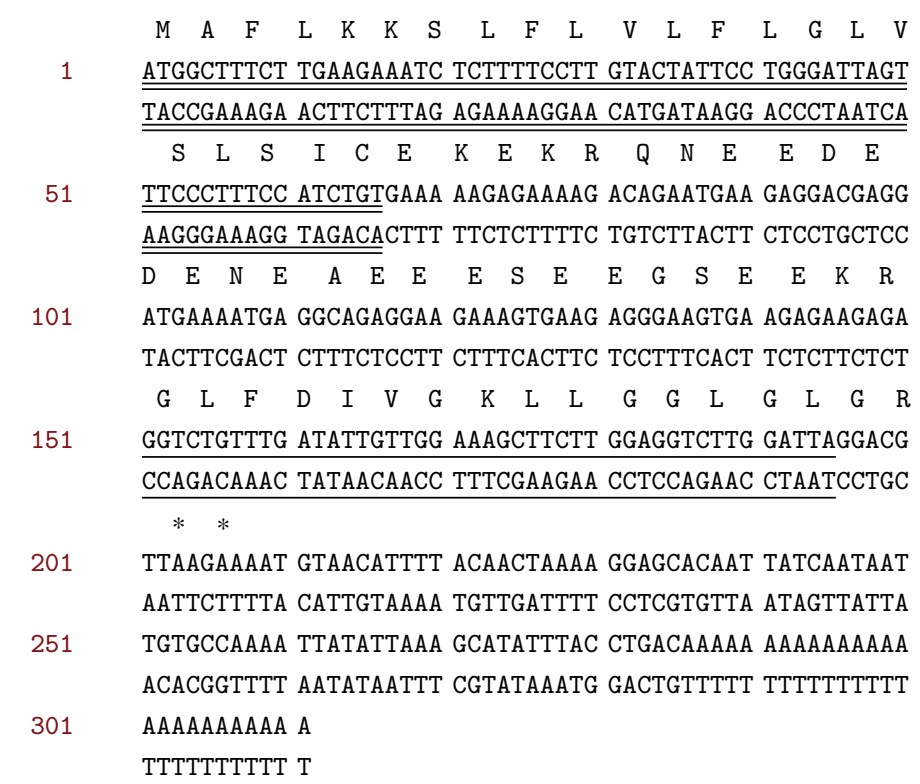

(c)

FIGURE 1: Nucleotide sequences of full-length cDNA clones encoding open-reading frames of (a) preprocaeridin-1, (b) preproS5-caeridin-1, and (c) preprocaerdin-al cloned from a Litoria caerulea (L. caerulea) skin secretion cDNA library. Putative signal peptide sequences are double-underlined, mature Caeridin sequences are single-underlined, and stop codons are indicated by asterisks.

for the evaluation of the antimicrobial activity of the novel peptides [15-17]. Bradykinin derived from the frog skin extract of the European grass frog (Rana temporaria) is the counterpart to mammalian bradykinins with no obvious antimicrobial activities; thus, it is incorporated as the negative peptide in the antimicrobial activity tests [18-20]. Caeridin-al exhibited different levels of antimicrobial activities against the growth of the tested microorganisms (Table 4) and demonstrated the most potent antimicrobial activity against Staphylococcus aureus (S. aureus). It also inhibited the growth of antibiotic-resistant bacteria, methicillin-resistant S. aureus (MRSA), and Enterococcus faecalis (E. faecalis), but slightly less potent than that against $S$. aureus. It also had antimicrobial activities against the Gram-negative bacterium, Escherichia coli (E. coli) and the yeast, Candida albicans (C. albicans). Caeridin-1 and S5Caeridin-1 did not demonstrate any antimicrobial activities on these tested microorganisms.

2.6. Membrane Permeability Studies. The novel antimicrobial peptide Caeridin-a1, melittin, and bradykinin were tested in the membrane permeability studies. Melittin is a canonical membrane interactive peptide, so it was included as the positive peptide [15-17]. Bradykinin was referred to as the negative peptide for it is known to be inactive on membrane interaction and permeabilisation [18-20].
2.6.1. Membrane Permeability Studies on S. aureus. The peptide-induced permeabilisation of the cytoplasmic membranes of $S$. aureus was detected using SYTOX Green, a counterpart stain of nucleic acid and an indicator of dead cells. The cell membrane of $S$. aureus remained intact after being treated with the purified synthetic Caeridin-a1 (MIC) for $2 \mathrm{~h}$, but became massively compromised after being treated with the purified synthetic Caeridin-al (MBC) for the same period of time, as shown in Figure 8. This phenomena suggested that Caeridin-al (MIC) failed to induce permeabilisation to the cytoplasmic membrane of $S$. aureus within the $2 \mathrm{~h}$ treatment. After the $2 \mathrm{~h}$ treatment, the positive peptide melittin produced approximately $50 \%$ membrane permeability at MIC $(1 \mu \mathrm{M})$ and $100 \%$ membrane permeability at MBC $(2 \mu \mathrm{M})$. The negative peptide bradykinin, Caeridin-1, and S5-Caeridin-1 barely showed membranepermeabilising activity up to $512 \mu \mathrm{M}$.

2.6.2. Membrane Permeability Tests on E. coli. The peptideinduced membrane permeabilisation of E. coli was determined by the release of $\beta$-galactosidase activity into culture medium MHB (2\% lactose) using ONPG as the substrate. As shown in Figure 9, the purified synthetic Caeridin-a1 (MIC and $\mathrm{MBC}$ ) induced inner membrane permeabilisation within $30 \mathrm{~min}$ given that the ONPG entered the cytoplasm and was degraded by $\beta$-galactosidase, generating 


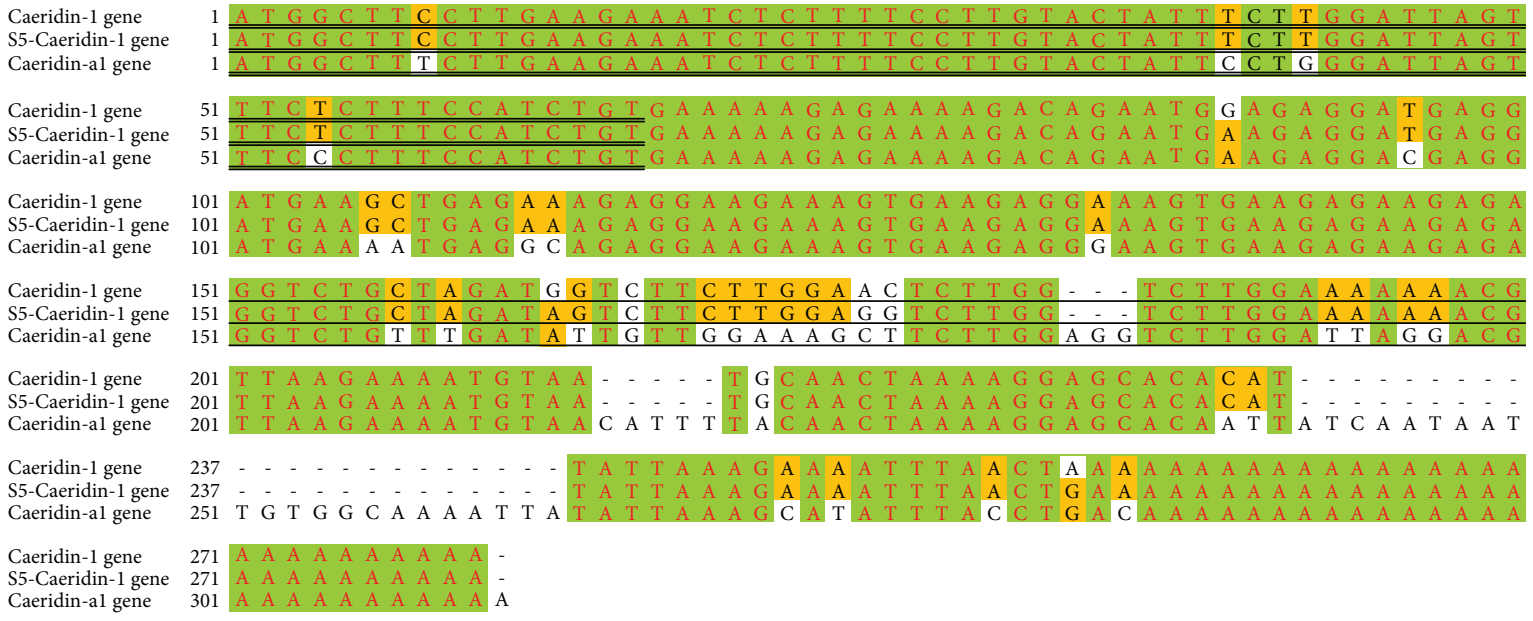

(a)

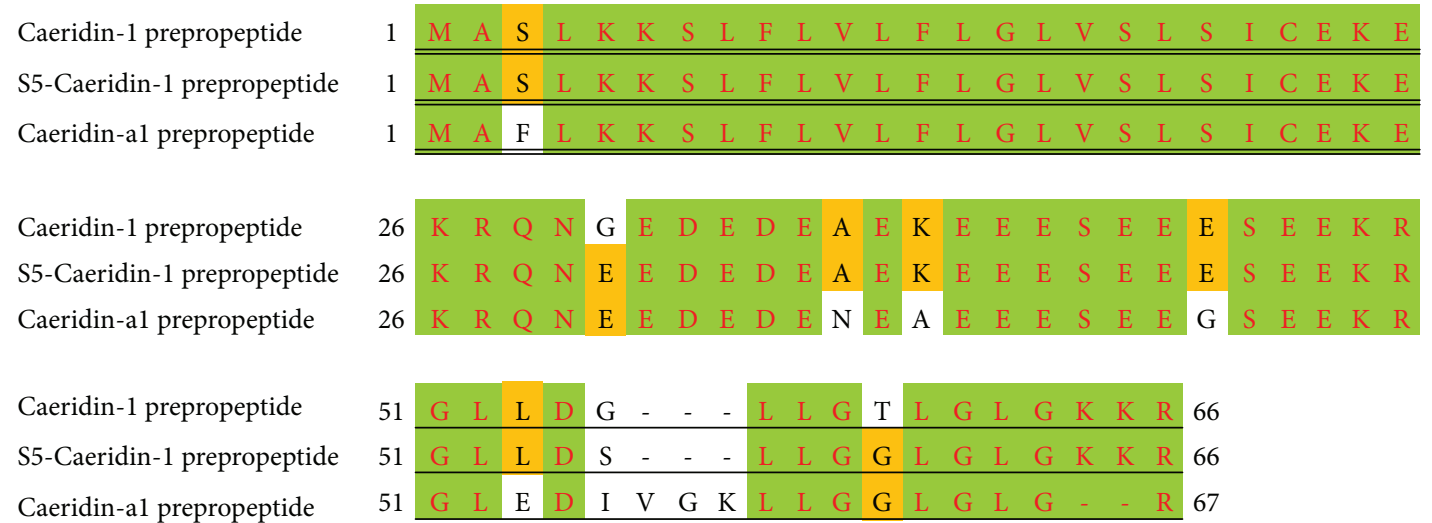

(b)

Figure 2: Alignments of (a) nucleotide sequences of cloned preprocaeridin cDNAs and (b) translated preprocaeridin open-reading frames established MEGA6. The identical and conservative regions are highlighted in green and yellow, respectively. Putative signal peptide sequences encoding regions and putative signal peptide sequences are double-underlined, and mature Caeridin sequences encoding regions and mature Caeridins are single-underlined.

$\begin{array}{lllllllllllllllll}\text { Caeridin-1 } & \text { G } & \text { L } & \text { L } & \text { D } & \text { G } & - & - & - & \text { L } & \text { L } & \text { G } & \text { T } & \text { L } & \text { G } & \text { L } \\ \text { S5-Caeridin-1 } & \text { G } & \text { L } & \text { L } & \text { D } & \text { S } & - & - & - & \text { L } & \text { L } & \text { G } & \text { G } & \text { L } & \text { G } & \text { L } \\ \text { Caeridin-a1 } & \text { G } & \text { L } & \text { F } & \text { D } & \text { I } & \text { V } & \text { G } & \text { K } & \text { L } & \text { L } & \text { G } & \text { G } & \text { L } & \text { G } & \text { L } \\ \text { Caeridin-2 } & \text { G } & \text { L } & \text { L } & \text { D } & \text { V } & \text { V } & \text { G } & \text { N } & \text { L } & \text { L } & \text { G } & \text { G } & \text { L } & \text { G } & \text { L } \\ \text { Caeridin-3 } & \text { G } & \text { L } & \text { F } & \text { D } & \text { A } & \text { I } & \text { G } & \text { N } & \text { L } & \text { L } & \text { G } & \text { G } & \text { L } & \text { G } & \text { L } \\ \text { Caeridin-4 } & \text { G } & \text { L } & \text { L } & \text { D } & \text { V } & \text { V } & \text { G } & \text { N } & \text { V } & \text { L } & \text { H } & \text { S } & \text { L } & \text { G } & \text { L } \\ \text { Caeridin-5 } & \text { G } & \text { L } & \text { L } & \text { G } & \text { M } & \text { V } & \text { G } & \text { S } & \text { L } & \text { L } & \text { G } & \text { G } & \text { L } & \text { G } & \text { L } \\ \text { Caeridin-6 } & \text { G } & \text { L } & \text { L } & \text { G } & \text { F } & \text { V } & \text { G } & \text { S } & \text { L } & \text { L } & \text { G } & \text { G } & \text { L } & \text { G } & \text { I } \\ \text { Caeridin-7.1 } & \text { G } & \text { L } & \text { L } & \text { D } & \text { M } & \text { V } & \text { T } & \text { G } & \text { L } & \text { L } & \text { G } & \text { N } & - & & & \text { L }\end{array}$

Figure 3: Alignments of amino acid sequences of Caeridins identified from L. caerulea. The identical and conservative amino acids were highlighted in green and orange, respectively.

o-nitrophenol that produced an absorbance at $420 \mathrm{~nm}$. The Caeridin-al-induced membrane permeabilisation of $E$. coli was not as strong as the positive peptide melittin, evidenced by the higher absorbance at $420 \mathrm{~nm}$, indicating an increased production of o-nitrophenol by ONPG hydrolysis. Caeridin-1, S5-Caeridin-1, and the negative peptide bradykinin 


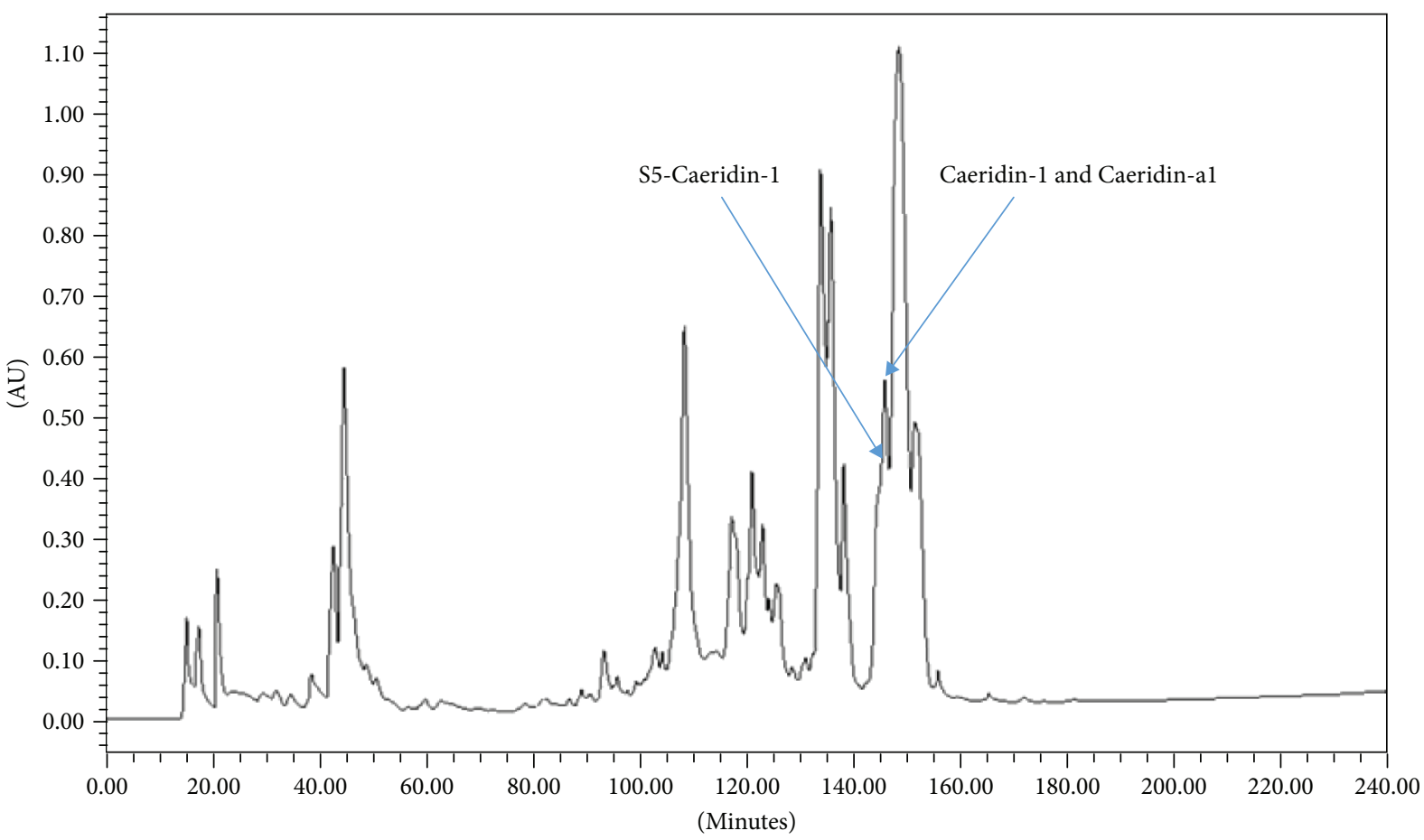

FIGURE 4: Reversed-phase high-performance liquid chromatography (HPLC) chromatogram of the skin secretion from L. caerulea. Caeridin1, S5-Caeridin-1, and Caeridin-al were eluted at approximately $144 \mathrm{~min}, 143 \mathrm{~min}$, and $144 \mathrm{~min}$, respectively. The $y$-axis shows the relative absorbance in absorbance units (AU) at a wavelength of $214 \mathrm{~nm}$, and the $x$-axis shows the retention time in minutes.

failed to induce membrane permeabilisation of E. coli, as no absorbance increase was observed at $420 \mathrm{~nm}$.

\subsubsection{Membrane Permeability Study on Human Microvascular} Endothelial Cell Line, HMEC-1. The peptide-induced membrane permeabilisation of normal human cells was evaluated by the release of lactate dehydrogenase (LDH), a cytosolic enzyme, from the damaged membrane of the human microvascular endothelial cell line HMEC-1. After treatment with Caeridin-1, S5-Caeridin-1, and negative peptide bradykinin at concentrations of $10^{-7} \mathrm{M}$ to $10^{-4} \mathrm{M}$, lower than $5 \%$ of membrane lysis was resulted (Figures 10(a), 10(b), and $10(\mathrm{e}))$. In comparision, Caeridin-al-induced membrane permeabilisation of HMEC-1 cells was indicated by about $50 \%$ of $\mathrm{LDH}$ release at $100 \mu \mathrm{M}$ and approximately $10 \% \mathrm{LDH}$ release at $10 \mu \mathrm{M}$ (Figure $10(\mathrm{c})$ ). The positive peptide melittin showed membrane permeability in HMEC-1 cells at a concentration as low as $0.1 \mu \mathrm{M}$, suggested by approximately $10 \% \mathrm{LDH}$ release (Figure 10(d)). As the level of LDH released into the medium is indicative of cytotoxicity, Caeridin-1, S5Caeridin-1, and negative peptide bradykinin showed weak cytotoxicity to HMEC-1 cells at $100 \mu \mathrm{M}$, while Caeridin-a1 and positive peptide melittin showed significant cytotoxicity at $100 \mu \mathrm{M}$. However, at the lower tested concentrations, no cytotoxicity was detected with Caeridins and negative peptide bradykinin.

2.7. Haemolysis Induced by Caeridins. Haemolytic activities of Caeridins, positive peptide melittin, and negative peptide bradykinin were studied using horse erythrocytes as shown in Figure 11. Melittin was incorporated as the positive peptide due to its known haemolytic activities. The amphibian bradykinin, the counterpart to mammalian Bradykinin, has so little haemolytic activities that it was included in the haemolysis test as the negative peptide [15-20]. The incorporation of melittin and bradykinin as positive and negative peptide provided evidence on the evaluation of the haemolytic activities of the novel peptides. Bradykinin, Caeridin-1, and S5-Caeridin-1 exhibited weak haemolytic activities at the tested concentrations, while Caeridin-al exhibited $18 \%$ haemolysis at $32 \mu \mathrm{M}$, and positive peptide Melittin showed eminent haemolysis from $1 \mu \mathrm{M}$.

\section{Discussion}

Peptides could offer multiple benefits over other drug treatments, such as higher potency, higher selectivity, a broader range of targets, potentially lower toxicity, lower accumulation in tissues, more abundance in chemical and biological diversity, discoverability at amino acid and nucleotide levels, and relatively low cost in production [2]. Thus, the future of many medicinal treatments could depend on the use of peptides and peptide-based drugs [21]. Frog skin secretions have been recognised as a valuable source of abundant bioactive peptides which are generally categorised and grouped into cytolytic peptides and pharmacologically active peptides [6]. Given their bioactive potential, there are now global efforts to minimise the observed global decline in frog populations through frog protection and environmental conservation strategies, along with the development of improved animal-friendly methods to conduct peptide discovery experiments from frog skin secretions [22-24]. 


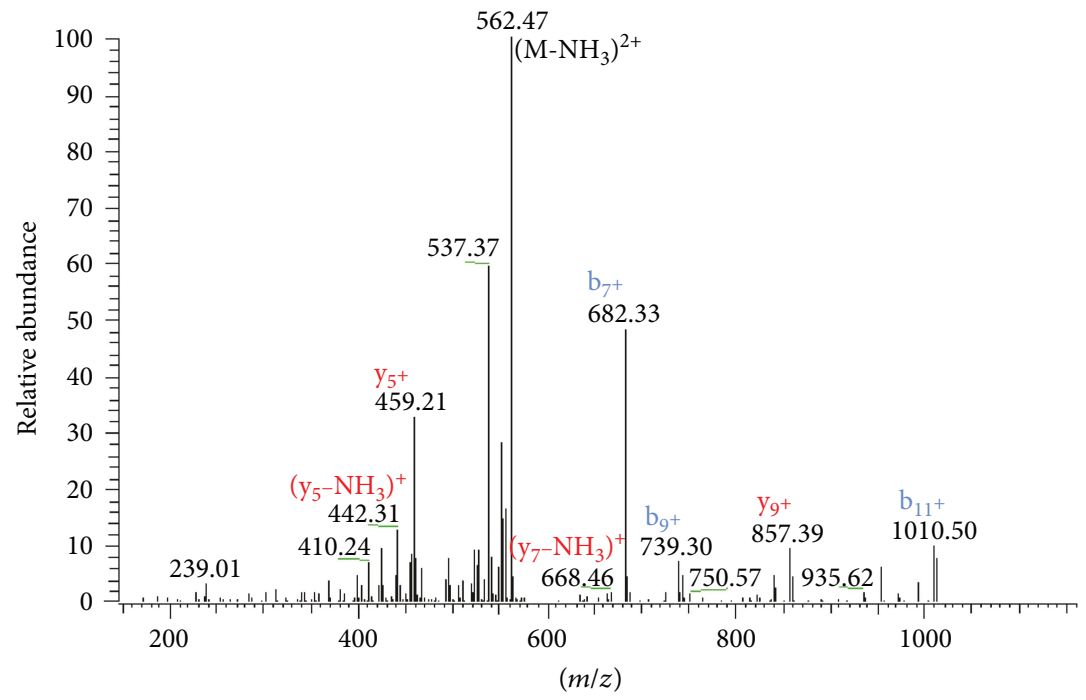

(a)

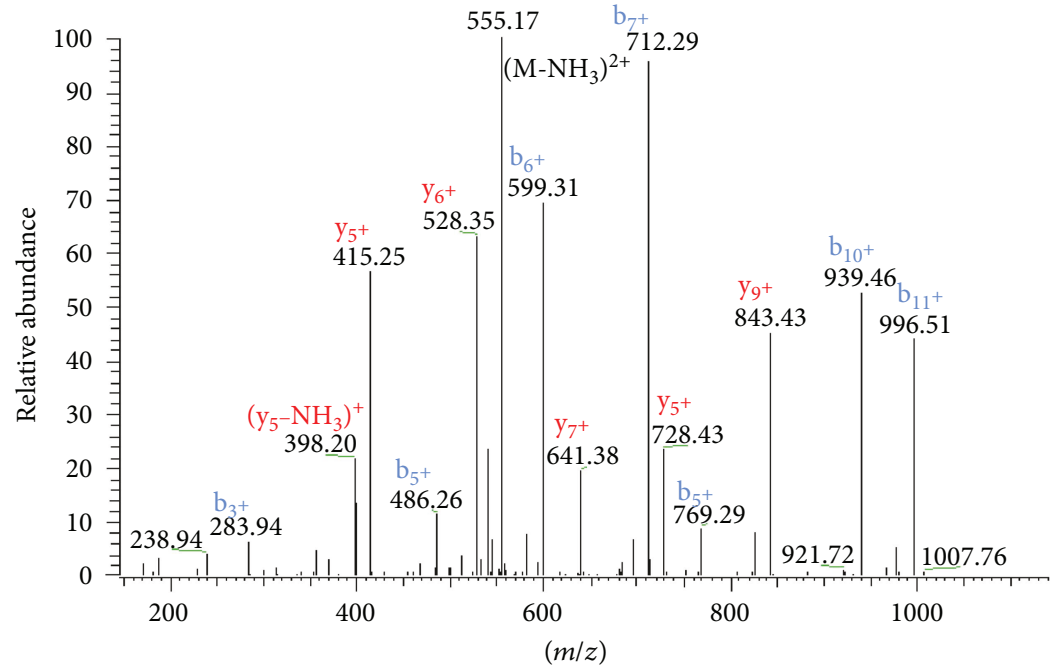

(b)

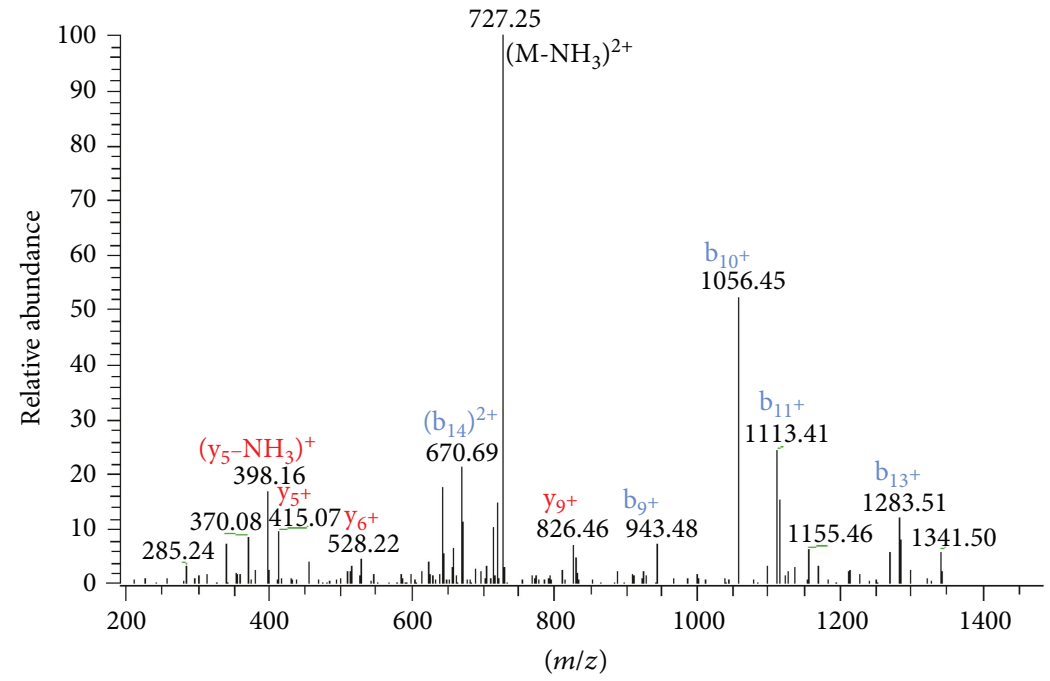

(c)

Figure 5: Annotated tandem mass (MS/MS) fragmentation spectrum of (a) Caeridin-1, (b) S5-Caeridin-1, and (c) Caeridin-a1. The observed $b$ ions and $y$ ions are labelled in blue and red, respectively. 
TABLE 1: Predicted singly and doubly charged $b$ ions and $y$ ions arising from MS/MS fragmentation of (a) Caeridin-1, (b) S5-Caeridin-1, and (c) Caeridin-a1. Actual fragment ions observed following MS/MS fragmentation are indicated in bold and italic.

\begin{tabular}{|c|c|c|c|c|c|c|}
\hline Number 1 & $\mathrm{~b}(1+)$ & $\mathrm{b}(2+)$ & Seq. & $y(1+)$ & $\mathrm{y}(2+)$ & Number 2 \\
\hline \multicolumn{7}{|c|}{ (a) } \\
\hline 1 & 58.03 & 29.52 & G & & & 12 \\
\hline 2 & 171.11 & 86.06 & $\mathrm{~L}$ & 1083.68 & 542.34 & 11 \\
\hline 3 & 284.20 & 142.60 & $\mathrm{~L}$ & 970.59 & 485.80 & 10 \\
\hline 4 & 399.27 & 200.12 & $\mathrm{D}$ & 857.39 & 429.26 & 9 \\
\hline 5 & 456.25 & 228.63 & G & 742.48 & 371.74 & 8 \\
\hline 6 & 569.33 & 285.17 & $\mathrm{~L}$ & 685.46 & 343.23 & 7 \\
\hline 7 & 682.33 & 341.71 & $\mathrm{~L}$ & 572.38 & 286.69 & 6 \\
\hline 8 & 739.30 & 370.22 & G & 459.21 & 230.15 & 5 \\
\hline 9 & 840.58 & 420.74 & $\mathrm{~T}$ & 402.27 & 201.64 & 4 \\
\hline 10 & 953.41 & 477.29 & $\mathrm{~L}$ & 301.22 & 151.12 & 3 \\
\hline 11 & 1010.50 & 505.80 & G & 188.05 & 94.57 & 2 \\
\hline 12 & & & L-Amidated & 131.12 & 66.06 & 1 \\
\hline \multicolumn{7}{|c|}{ (b) } \\
\hline 1 & 58.03 & 29.52 & G & & & 12 \\
\hline 2 & 171.11 & 86.06 & $\mathrm{~L}$ & 1069.66 & 535.33 & 11 \\
\hline 3 & 283.94 & 142.60 & $\mathrm{~L}$ & 956.58 & 478.79 & 10 \\
\hline 4 & 399.22 & 200.12 & $\mathrm{D}$ & 843.43 & 422.25 & 9 \\
\hline 5 & 486.26 & 243.63 & S & 728.43 & 364.74 & 8 \\
\hline 6 & 599.31 & 300.17 & $\mathrm{~L}$ & 641.38 & 321.22 & 7 \\
\hline 7 & 712.42 & 356.72 & $\mathrm{~L}$ & 528.35 & 264.68 & 6 \\
\hline 8 & 769.29 & 385.23 & G & 415.25 & 208.14 & 5 \\
\hline 9 & 826.47 & 413.74 & G & 358.25 & 179.63 & 4 \\
\hline 10 & 939.46 & 470.28 & $\mathrm{~L}$ & 301.22 & 151.12 & 3 \\
\hline 11 & 996.51 & 498.79 & G & 188.14 & 94.57 & 2 \\
\hline 12 & & & L-Amidated & 131.12 & 66.06 & 1 \\
\hline \multicolumn{7}{|c|}{ (c) } \\
\hline 1 & 58.03 & 29.52 & G & & & 15 \\
\hline 2 & 171.11 & 86.06 & $\mathrm{~L}$ & 1413.88 & 707.44 & 14 \\
\hline 3 & 318.18 & 160.09 & $\mathrm{~F}$ & 1300.79 & 650.90 & 13 \\
\hline 4 & 433.21 & 217.61 & $\mathrm{D}$ & 1153.73 & 577.67 & 12 \\
\hline 5 & 546.29 & 274.15 & I & 1038.70 & 519.86 & 11 \\
\hline 6 & 645.36 & 323.68 & $\mathrm{~V}$ & 925.62 & 463.31 & 10 \\
\hline 7 & 702.38 & 352.19 & G & 826.46 & 413.78 & 9 \\
\hline 8 & 830.48 & 415.7 & K & 769.53 & 385.27 & 8 \\
\hline 9 & 943.48 & 472.3 & $\mathrm{~L}$ & 641.38 & 321.22 & 7 \\
\hline 10 & 1056.45 & 528.8 & $\mathrm{~L}$ & 528.22 & 264.68 & 6 \\
\hline 11 & 1113.41 & 557.3 & G & 415.07 & 208.14 & 5 \\
\hline 12 & 1169.48 & 585.9 & G & 358.25 & 179.63 & 4 \\
\hline 13 & 1283.51 & 642.2 & $\mathrm{~L}$ & 301.22 & 151.12 & 3 \\
\hline 14 & 1340.79 & 670.7 & G & 188.05 & 94.57 & 2 \\
\hline 15 & & & L-Amidated & 131.12 & 66.06 & 1 \\
\hline
\end{tabular}

Within this study, we have successfully constructed a cDNA library of the lyophilized skin secretion of the Australian White's tree frog, L. caerulea. L. caerulea, a member of the tree frog family Hylidae, was selected for analysis as it has been understudied to date and has multiple skin-defensive and regulatory compounds with significant pharmaceutical potentials that warrant further investigation $[25,26]$. So far, three major peptide families have been identified from L. caerulea, namely, Caerins, Caeruleins, and Caeridins [9]. Caerins were found similar in primary structures with conserved -Gly-Leu- at the N-terminus, and they possess sufficient physiochemical characteristics to carry out 


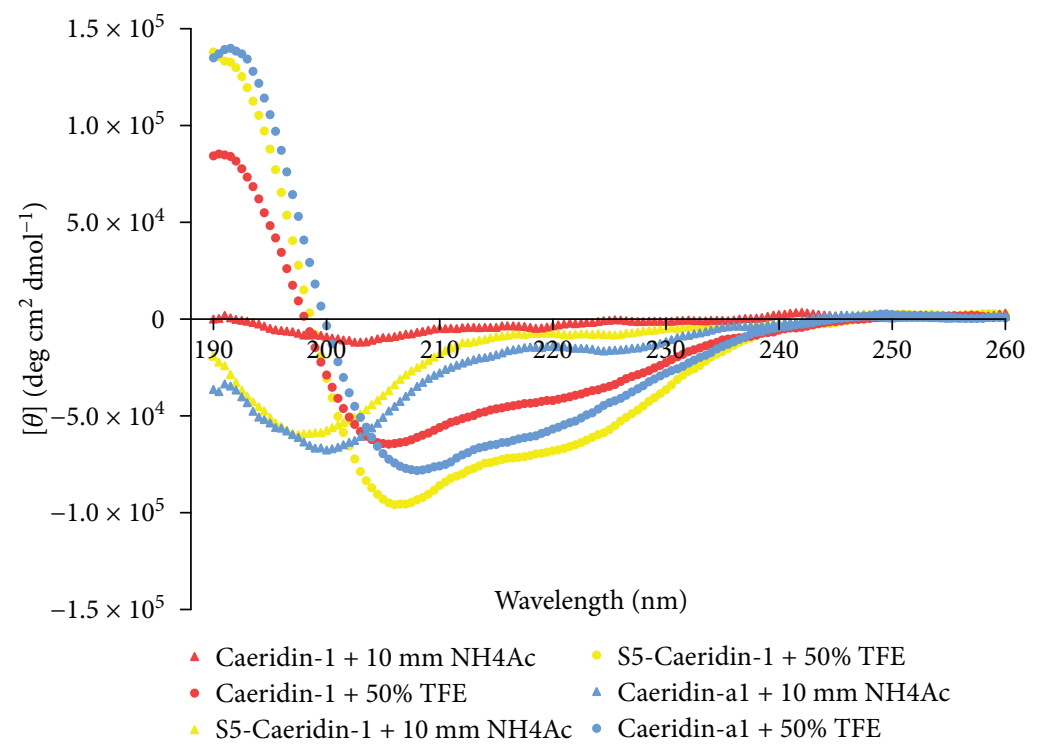

Figure 6: CD spectra under different conditions measured from $260 \mathrm{~nm}$ to $190 \mathrm{~nm}$ and plotted as mean residue ellipticity [ $\theta$ ] versus wavelength.

TABLE 2: Secondary structures of Caeridin-1, S5-Caeridin-1, and Caeridin-a1 deduced from CD spectra by K2D3 programme.

\begin{tabular}{lccc}
\hline Peptide & Method & $\alpha$ & $\beta$ \\
\hline Caeridin-1 & K2D3 & $86.68 \%$ & $0.02 \%$ \\
S5-Caeridin-1 & K2D3 & $94.98 \%$ & $0.01 \%$ \\
Caeridin-a1 & K2D3 & $95.13 \%$ & $0.02 \%$ \\
\hline
\end{tabular}

$\alpha=$ helices; $\beta=$ strands.

antimicrobial activities [27]. Caeruleins, similar to the mammalian cholecystokinin-8 (CCK-8) and hexagastrin, were proven as powerful pharmacological peptides inducing gastrointestinal smooth muscle contractions and analgesic and hormonal activities [28]. Caeridins, unfortunately, were reported to have neither antimicrobial activities nor pharmacologically active activities [9]. From the constructed cDNA, we have consistently cloned three different preprocaeridin cDNAs by means of a $3^{\prime}$-RACE strategy, using a degenerate sense primer pool designed to a conserved nucleotide sequence in the $5^{\prime}$ untranslated region of homologous Caerin cDNA. These clones contained full-length open-reading frames of preprocaeridins. The signal peptide primary structures and nucleic acid sequences are highly conserved and some are identical, and the conserved trends extend to the acidic prosegments, but not very obviously conserved when it comes to mature peptide encoding regions, as shown in Figure 2. All these mature peptides deduced from cloned skin secretion CDNAs were found to have a C-terminal amidation in the corresponding reversed-phase HPLC fractions by the subsequent mass spectrometric analysis as shown in Figures 5 and 6 . These mature peptides were subsequently compared with the protein database of the National Center of Biotechnology Information (NCBI), and it was found that one of these mature peptides was identical to Caeridin-1 with unknown transcriptomic information [9], here also called
Caeridin-1. The peptide with two amino acids different from Caeridin-1 was called S5-Caeridin-1, and the final peptide with $80 \%$ identity to Caeridin-2 and Caeridin-3 was called Caeridin-a1.

The chemical synthetic replicates of Caeridin-1, S5Caeridin-1, and Caeridin-a1 were tested through various bioassays. Antimicrobial activities of these Caeridins were screened on standard bacteria and drug-resistant bacteria given that peptides have previously shown potential to be developed as conventional antibiotic alternatives to unravel the global antimicrobial resistance. Smooth muscle is of great significance in physiological modulation; for example, the smooth muscle in the uterus helps in parturition, the smooth muscle in the bladder helps in uresis, the smooth muscle in arteries determines blood flow, and the smooth muscle in the digestive tract modulate nutrients and wastes mobility. Therefore, pharmacological activities of these Caeridins were tested on different rat smooth muscles.

Caeridin-1 and S5-Caeridin-1, deficient of physiochemical properties, were found to have no effects on membrane interaction and disruption and thus failed to show antimicrobial activities [29]. However, Caeridin-1 was found to mediate a contraction of rat urinary bladder smooth muscle with $\mathrm{EC}_{50}=5.6 \mathrm{nM}$ and a maximum contraction of $0.3 \mathrm{~g}$ in tension change with no haemolytic effects. S5-Caeridin-1 was found to induce a relaxation of rat ileum smooth muscle with $\mathrm{EC}_{50}=9.5 \mathrm{nM}$ and a maximum relaxation of $0.2 \mathrm{~g}$ in tension change with no haemolysis. The discovery of Caeridin-1 and S5-Caeridin-1 provided templates for developing urinary system and digestive system regulatory drugs, but the mechanisms of action need further investigations.

Caeridin-al was recognised to be neutral in charge, with a basic amino acid, -Lys-, and an acidic amino acid, -Asp-, and adopted $\alpha$-helical conformation in the membranemimetic environment. Caeridin-al was found to be inhibitory against the growth of normal microorganisms, the 
Table 3: Physicochemical properties of Caeridins determined by Heliquest.

\begin{tabular}{lcccc}
\hline Peptides & Hydrophobicity & Hydrophobic moment & Net charge & Charged residues \\
\hline Caeridin-1 & 0.807 & 0.417 & -1 & ASP 1 \\
S5-Caeridin-1 & 0.783 & 0.413 & -1 & ASP 1 \\
Caeridin-a1 & 0.77 & 0.477 & 0 & ASP 1, LYS 1 \\
Caeridin-2 & 0.751 & 0.45 & -1 & ASP 1 \\
Caeridin-3 & 0.735 & 0.489 & -1 & ASP 1 \\
Caeridin-4 & 0.725 & 0.421 & -1 & ASP 1 \\
Caeridin-5 & 0.841 & 0.369 & 0 & none \\
Caeridin-6 & 0.878 & 0.377 & 0 & none \\
Caeridin-7.1 & 0.757 & 0.615 & -1 & ASP 1 \\
\hline
\end{tabular}

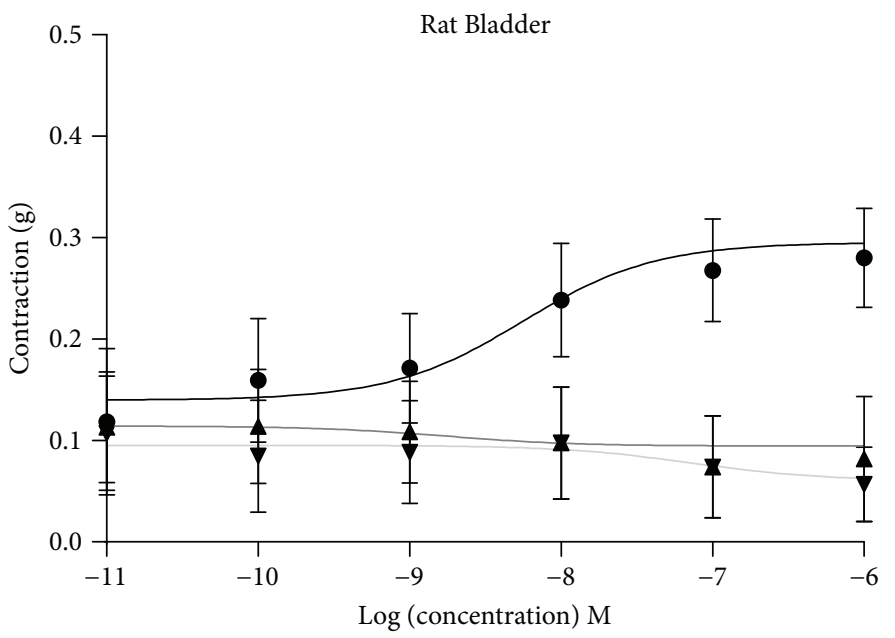

- Caeridin-1

$\Delta$ S5-Caeridin-1

$\boldsymbol{\nabla}$ Caeridin-al

(a)

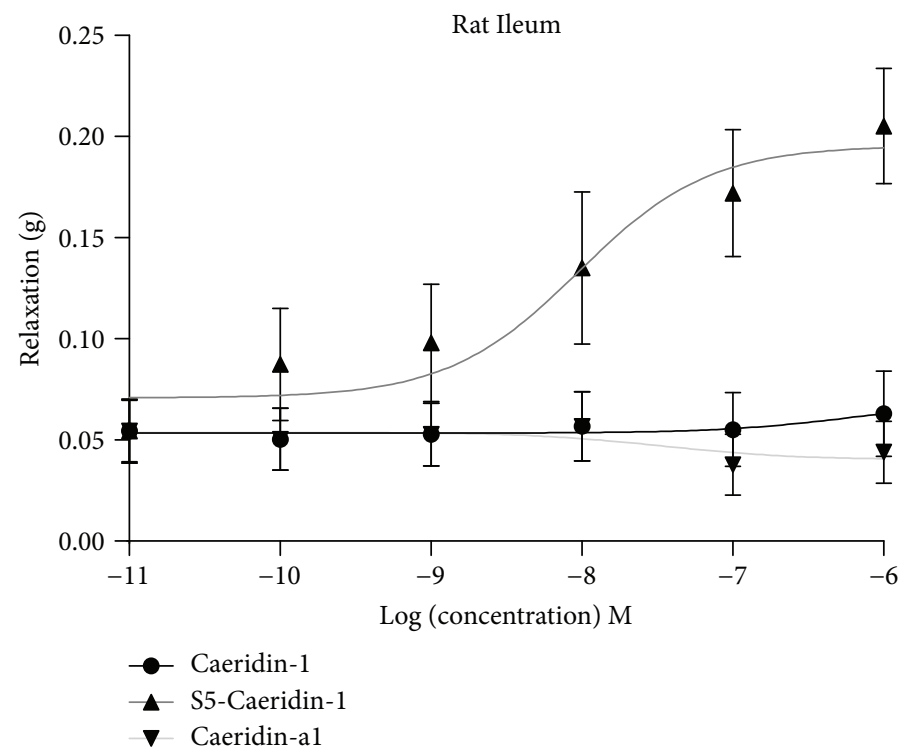

(b)

Figure 7: Dose-response curves of (a) synthetic Caeridins using rat urinary bladder smooth muscle preparations and (b) synthetic Caeridins on rat ileum smooth muscle preparations. Each point represents the mean and standard error of mean (SEM) of 5 determinations. 
TABLE 4: Minimum inhibitory concentration (MIC) and minimum bactericidal concentration (MBC) of Caeridins, melittin, and bradykinin against different tested microorganisms.

\begin{tabular}{lccccc}
\hline \multirow{2}{*}{ Peptides } & & \multicolumn{2}{c}{ MIC/MBC $(\mu \mathrm{M})$} & \multicolumn{2}{c}{ MIC/MFC $(\mu \mathrm{M})$} \\
& S. aureus NCTC10788 & MRSA NCTC12493 & E. faecalis NCTC12697 & E. coli NCTC10418 & C. albicans NCYC1467 \\
\hline Caeridin-a1 & $8 / 16$ & $16 / 32$ & $32 / 64$ & $32 / 64$ & $32 / 64$ \\
S5-Caeridin-1 & $>512 />512$ & $>512 />512$ & $>512 />512$ & $>512 />512$ & $>512 />512$ \\
Caeridin-1 & $>512 />512$ & $>512 />512$ & $>512 />512$ & $>512 />512$ & $>512 />512$ \\
Melittin & $1 / 2$ & $2 / 4$ & $2 / 4$ & $4 / 8$ & $1 / 8$ \\
Bradykinin & $>512 />512$ & $>512 />512$ & $>512 />512$ & $>512 />512$ & $>512 />512$ \\
\hline
\end{tabular}

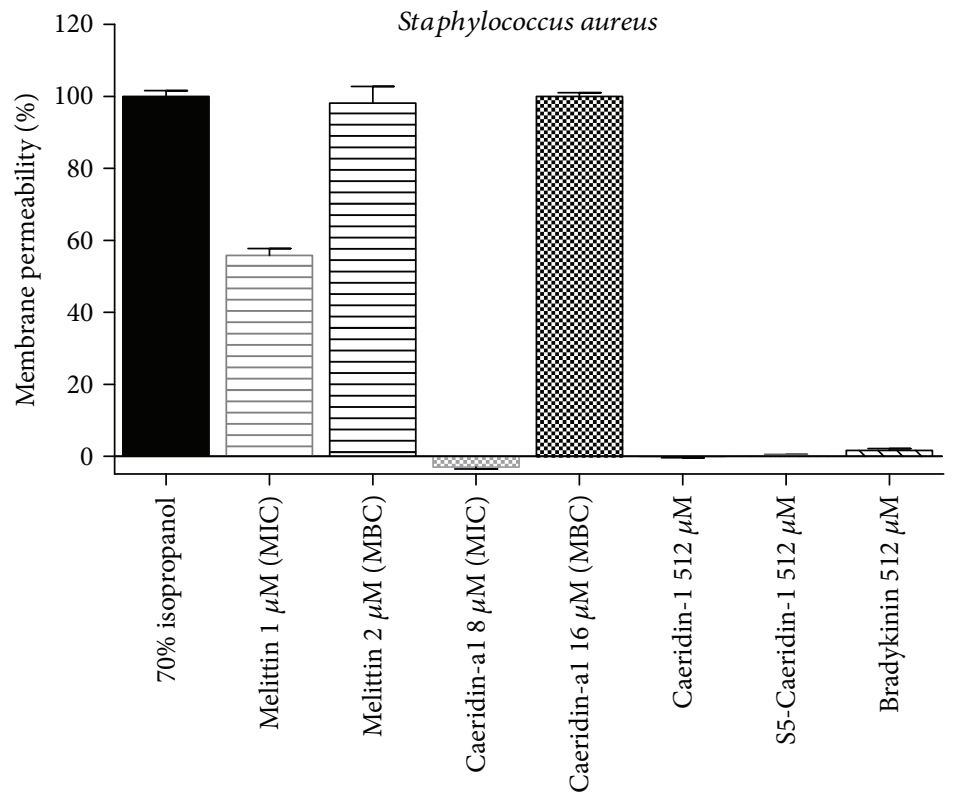

FIGURE 8: Membrane permeabilisation of $S$. aureus treated with melittin (MIC $=1 \mu \mathrm{M}$ and $\mathrm{MBC}=2 \mu \mathrm{M})$, Caeridin-a1 $(\mathrm{MIC}=8 \mu \mathrm{M}$ and $\mathrm{MBC}=16 \mu \mathrm{M})$, Caeridin-1 $(512 \mu \mathrm{M})$, S5-Caeridin-1 $(512 \mu \mathrm{M})$, bradykinin $(512 \mu \mathrm{M})$, and $70 \%$ isopropanol for $2 \mathrm{~h}$. The degree of membrane permeability was calculated in comparison with the maximum membrane permeabilisation control (70\% isopropanol-treated). The error bars represent SEM of three independent experiments and each experiment with five replicates.

Gram-positive bacterium, S. aureus, the Gram-negative bacterium, E. coli, and the yeast, C. albicans, as well as against MRSA and $\beta$-lactam-resistant bacterium E. faecalis which are hard to be controlled by conventional antibiotics and tend to cause more virulent infections. Antimicrobial susceptibility tests suggest that Caeridin-a1 showed better antimicrobial potency against the Grampositive bacteria, S. aureus, MRSA, and E. faecalis, with MIC at $8 \mu \mathrm{M}, 16 \mu \mathrm{M}$, and $32 \mu \mathrm{M}$, respectively, but less potent against the Gram-negative bacterium, E. coli, with $\mathrm{MIC}$ at $32 \mu \mathrm{M}$. As the membrane disruption is recognised as one of the mechanisms of antimicrobial actions of antimicrobial peptides, membrane permeability tests were performed on the standard Gram-positive bacterium ( $S$. aureus) and Gram-negative bacterium (E. coli). The Caeridin-a1-induced membrane permeabilisation of $S$. aureus was monitored only at its $\mathrm{MBC}(16 \mu \mathrm{M})$, indicating that Caeridin-al at its $\mathrm{MIC}=8 \mu \mathrm{M}$ was not able to permeabilise the cytoplasmic membrane within $2 \mathrm{~h}$. However, Caeridin-al induced membrane permeabilisation of $E$. coli within $30 \mathrm{~min}$ at both its MIC $(32 \mu \mathrm{M})$ and MBC $(64 \mu \mathrm{M})$ against $E$. coli. The significant membrane-disruptive effect of Caeridin-a1 was also observed in HMEC-1 cells at $100 \mu \mathrm{M}$ and was weakened with the decrease of the peptide concentration. These results suggest that the swift membrane permeability depends on the administrated concentration of Caeridin-a1. Caeridin-al at its higher concentrations could rapidly and unspecifically interact and disrupt the cytoplasmic membrane leading to cell lysis, but Caeridin-a1 at its lower concentrations may perform antimicrobial activities by other mechanisms or may need longer time to induce membrane permeabilisation. Caeridin-al was also found to induce haemolysis at higher concentrations, whereby $18 \%$ haemolysis was detected at $32 \mu \mathrm{M}$, which consequently decreases its potential therapeutic value. However, the size of Caeridin-a1 is relatively small with only 15 amino acid residues, and therefore, Caeridin-al could be used as a template for developing smaller antimicrobial peptides after rational structural modification, which may be of interest to the pharmaceutical industry due to reduced cost of development and easier manufacturing processes. 


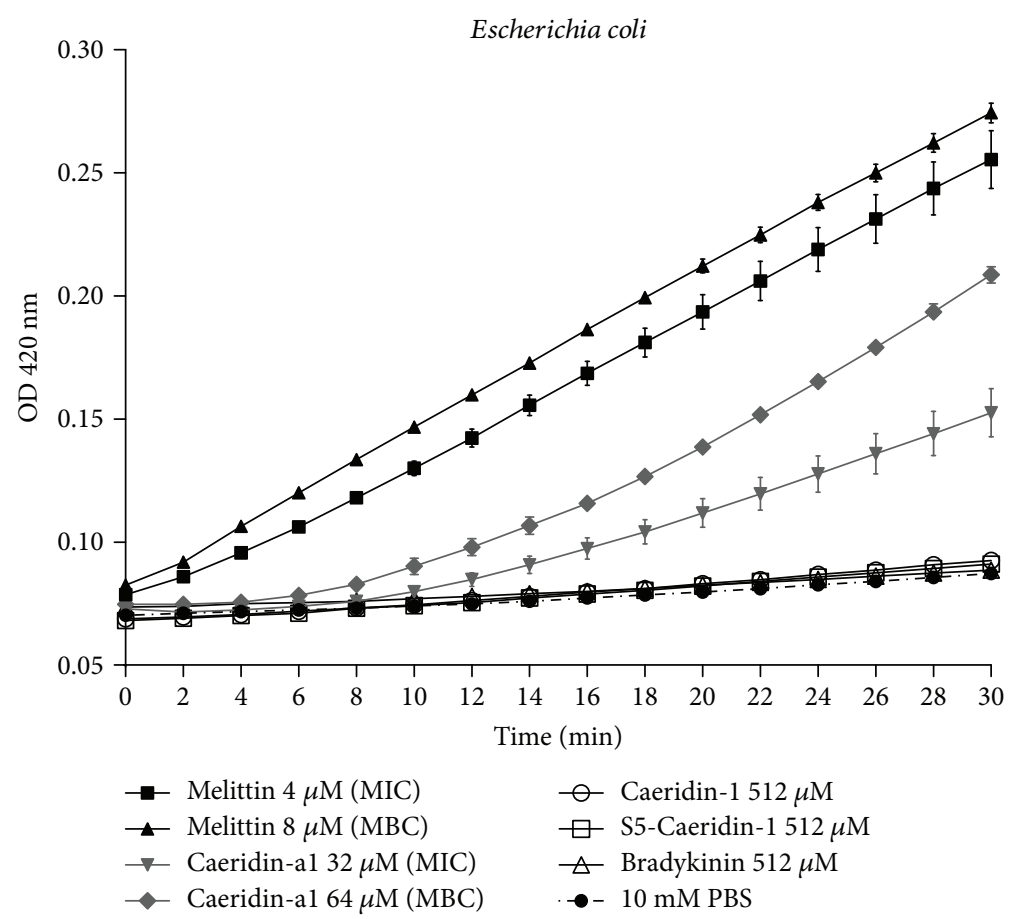

Figure 9: Membrane permeabilisation of E. coli treated with Caeridin-a1, Caeridin-1, S5-Caeridin-1, melittin, and bradykinin. The hydrolysis of ONPG generated by the release of cytoplasmic $\beta$-galactosidase of E. coli after treatment at MIC and MBC of Caeridin-a1, MIC and MBC of melittin, and maximum tested concentration of Caeridin-1, S5-Caeridin-1, and bradykinin was measured spectroscopically at $420 \mathrm{~nm}$ UV for $30 \mathrm{~min}$. Each point represents mean absorbance and SEM of three independent experiments and each experiment with five replicates.

Although the Caeridins discovered in this study share a similar amino acid composition and structural elements with each other and with the Caeridins reported previously, the bioactivities they exhibited are different. Only Caeridin-a1 was found to demonstrate potent antimicrobial and haemolytic effects, but Caeridin-1, S5-Caeridin-1, and other reported Caeridins were not. This could be explained by the variation in the membrane-disruptive action of peptides. The Gram-positive bacterial cell walls contain anionic teichoic acids and lipoteichoic acids. The anionic lipopolysaccharides are widely distributed in the outer leaflet of the outer membrane of Gram-negative bacteria. The negatively charged glycosaminoglycans and gangliosides are composed in mammalian cells exterior to the cytoplasmic membrane. Firstly, amphipathic peptides with positively charged residues are attracted to the vicinity of the cell surface by electrostatic actions. Secondly, peptides attach to the cell membrane via electrostatic and hydrophobic interactions. Then they undergo conformational transition to bind with the membrane and form transmembrane pores/channels or translocate phospholipid bilayers, thus destroying the membrane integrity. Because of the abundance of the acidic phospholipids, such as cardiolipin and phosphatidylglycerol, and the absence of sterol, in the cytoplasmic membrane of bacteria, amphipathic peptides with cationic residues are able to attach to the bacterial membrane by both electrostatic interaction and hydrophobic interaction. However, the mammalian cell membranes only have acidic phospholipids at the inner facet of the phospholipid bilayers, suggesting that peptides are more able to interact with the mammalian cell membrane by hydrophobic interaction. In addition to phospholipids, the numerous sterols embedded in the bilayers impede the peptide from better binding with the membrane and triggering further membrane disruption, which is the same on red blood cells. The cationic residue, -Lys-, in the amino acid composition of Caeridin-a1 may facilitate the peptide being better attracted to the cell surface and interacting with the cell membrane by electrostatic effects, though the net charge of Caeridin-a1 was 0 due to the presence of the anionic residue, -Asp-. In addition to electrostatic interaction, the high amphipathicity and hydrophobicity of Caeridin-al may also promote the peptide to bind to the cell membrane by hydrophobic interaction. Then, Caeridin-al may conform to an $\alpha$ helical structure to bind with the membrane and form transmembrane pores, thus destroying the membrane. Therefore, Caeridin-a1 was able to disrupt the non-sterol-protected bacterial cell membrane at lower concentrations, and sterol/cholesterol-protected mammalian cell membrane and red blood cell membrane at higher concentrations, showing antimicrobial effects on the tested microorganisms, cytotoxic effects on HMEC-1 cells, and haemolytic effects on the horse erythrocytes. Regarding the other Caeridins, as shown in Table 3, the net charge of Caeridin-1, S5-Caeridin-1, Caeridin-2-4, and Caeridin-7.1 is -1 due to the presence of an acidic residue, -Asp-, and the net charge of Caeridin-5 and Caeridin- 6 is zero because of the lack of charged residues. Therefore, these Caeridins are expected to fail to undergo electrostatic attraction and interaction with the membrane. They showed no membrane disruption in the tested microorganisms, mammalian cells, and horse red blood cells. 


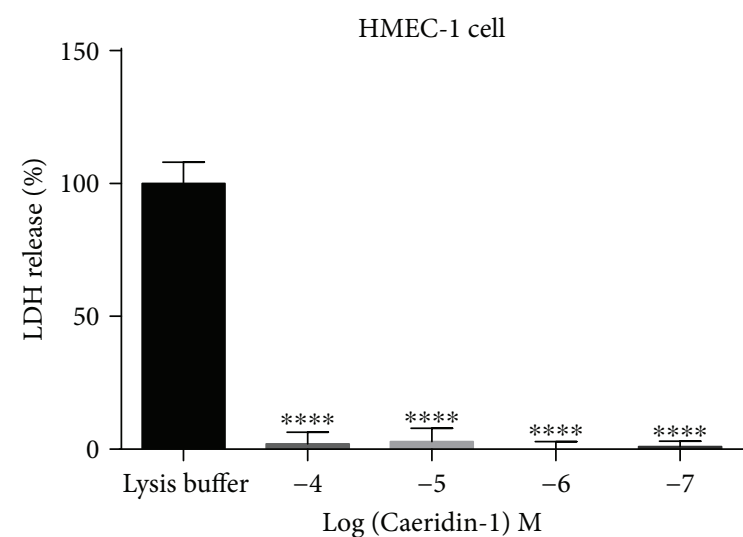

(a)

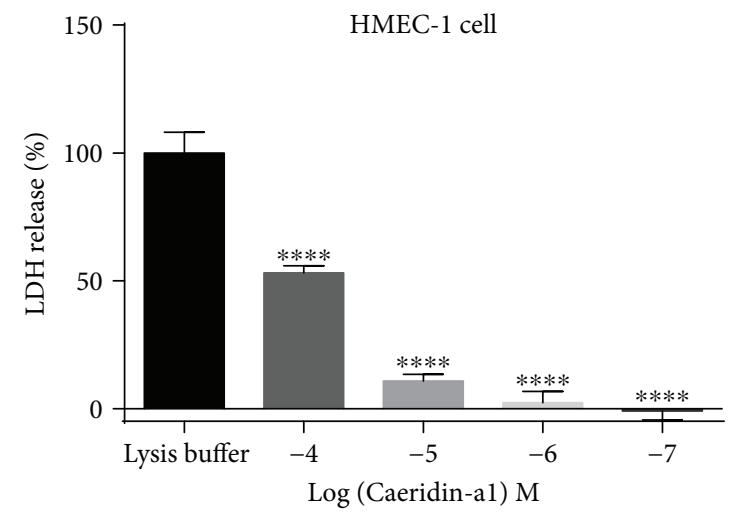

(c)

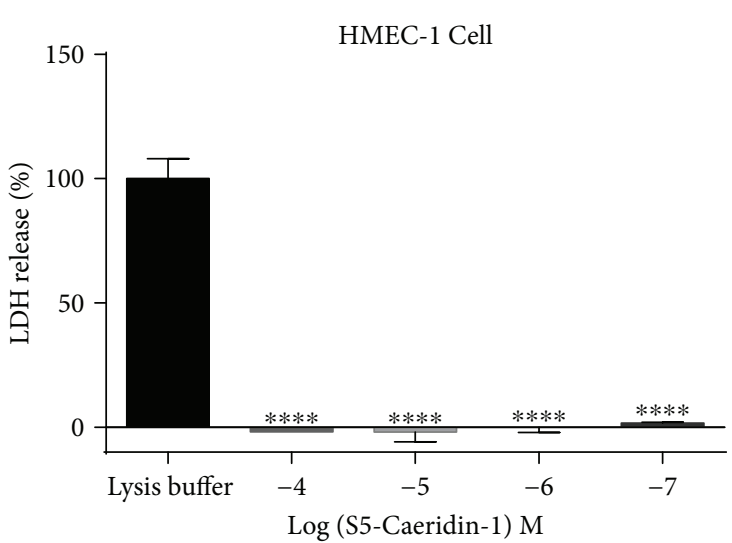

(b)

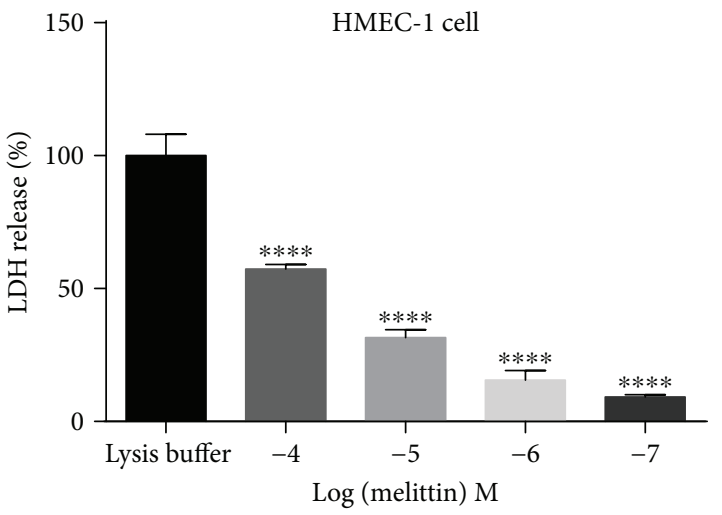

(d)

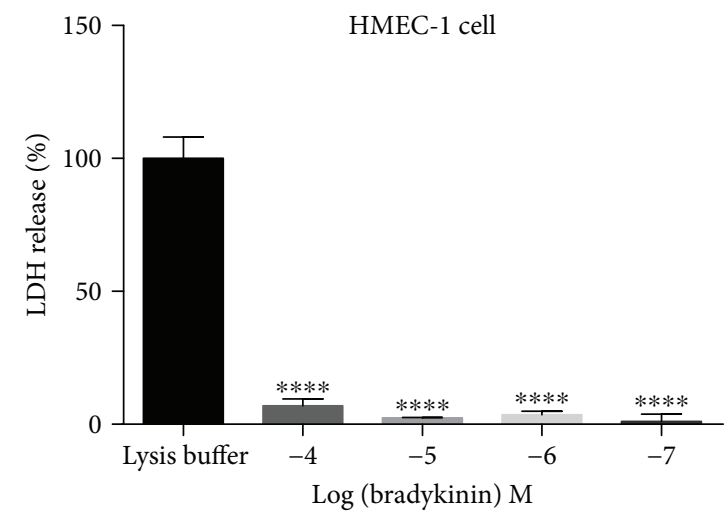

(e)

FIGURE 10: Membrane permeabilisation of human microvascular endothelial cell line, HMEC-1, reflected by the level of LDH released into the medium, after being treated by (a) Caeridin-1, (b) S5-Caeridin-1, (c) Caeridin-a1, (d) positive peptide melittin, and (e) negative peptide Bradykinin. The level of LDH release was calculated in comparison with the maximum LDH release control group (lysis buffer-treated)). ${ }^{* * * *} p<0.0001$ represents a significant change in the level of LDH release, compared with the maximum LDH release control group (lysis buffer-treated), using one-way analysis of variance followed by Dunnett's multiple comparisons tests. The error bar represents SEM of three independent experiment determinations and each experiment with triplicates.

Although no antimicrobial effects were detected, Caeridin-1 and S5-Caeridin-1 were presumed to be mediated by the G protein-coupled receptors to induce contraction and relaxation of smooth muscle preparations with no haemolysis and cytotoxicity. However, Caeridin-al with strong membrane disruptive activity would also cause damage to smooth muscle cell membrane; thus, no smooth muscle activities were found with Caeridin-a1.
The discovery of Caeridin-1, S5-Caeridin-1, and Caeridin-a1 reinforced the multiple bioactivities of the Caeridin peptide family. Although they are very similar with other reported Caeridins, certain amino acid mutations were identified. It is these small mutations in amino acid sequences and compositions that affect physicochemical characteristics and functioning structures and lead to big differences in bioactivities. Therefore, optimal amino acid sequence selections from 


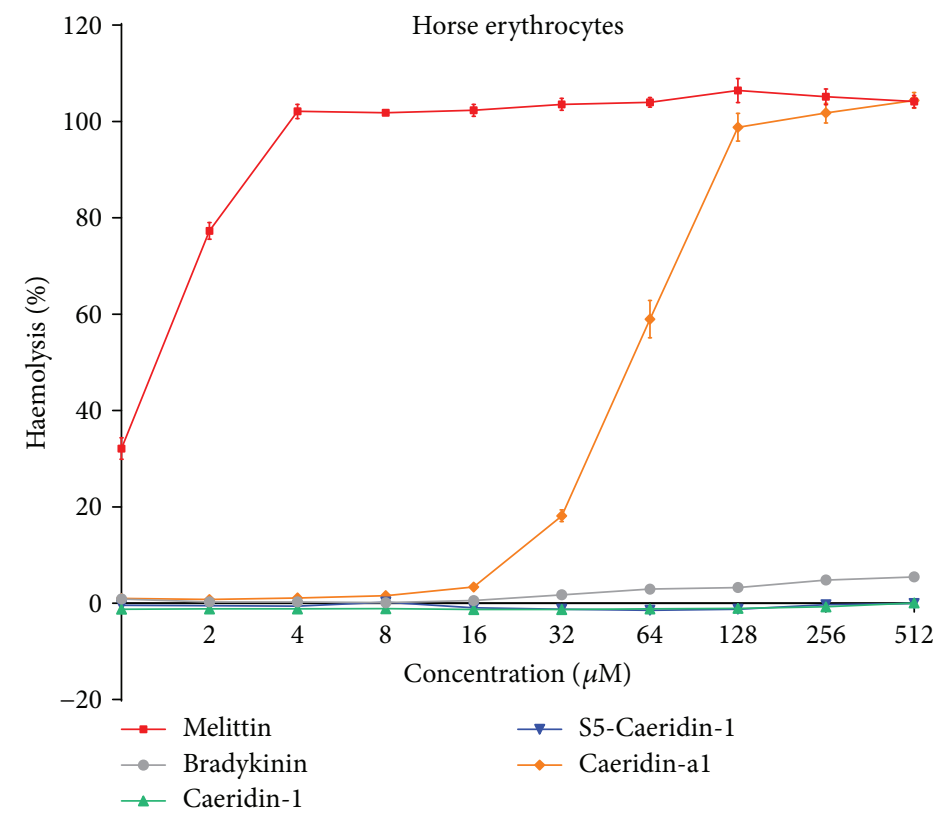

FIGURE 11: Haemolytic activities of synthetic Caeridin-1, S5-Caeridin-1, Caeridin-a1, melittin, and bradykinin. The level of haemolysis tested on horse red blood cells was calculated in comparison with the maximum haemolysis control (1\% Triton X-100-treated). The error bar represents SEM of three independent experiment determinations and each experiment with five replicates.

frog skin secretions lay a foundation for peptide discovery and development.

\section{Materials and Methods}

4.1. Collection of Frog Skin Secretions. The adult Australian frogs $(n=4)$, L. caerulea, were captive bred and kept for three months before the collection of their skin secretions. Their defensive skin secretions were collected from their dorsal skin by mild transdermal electrical stimulation according to the technique reported by Tyler et al. [30], then lyophilised and stored at $-20^{\circ} \mathrm{C}$ prior to analysis. Sampling of skin secretion was performed by Mei Zhou under UK Animal (Scientific Procedures) Act 1986, project license PPL 2800, issued by the Department of Health, Social Services and Public Safety, Northern Ireland. Procedures had been vetted by the IACUC of Queen's University Belfast and approved on 19 February 2016.

4.2. "Shotgun" Cloning of Novel Caeridin Precursor-Encoding cDNAs from the Skin Secretion-Derived cDNA Library of L. caerulea. The cDNA library of $L$. caerulea was established through the reverse transcription of the mRNA. The mRNA was extracted from the lyophilised skin secretion by using Dynabeads $^{\circledR}$ mRNA DIRECT ${ }^{\mathrm{TM}}$ Kit (Life Technologies, Oslo, Norway). The extracted mRNA was reverse transcribed to synthesise the first-strand CDNA by following the instructions described by the BD SMART ${ }^{\mathrm{TM}}$ RACE cDNA Amplification Kit (Clontech, Palo Alto, CA, USA) to establish the cDNA library. The cDNA library was subjected to $3^{\prime}$-RACE (rapid amplification of cDNA ends) procedures to obtain full-length preprocaeridin nucleic acid sequence data with a SMART-RACE Kit (Clontech, Palo Alto, CA, USA) according to the manufacturer, which involved a NUP primer supplied with the kit and a degenerate sense primer pool (S1: $5^{\prime}$-GVCCTTGTAAAGACCAAVCATGGCTT-3') designed to a segment of the $5^{\prime}$-untranslated region of Caerin cDNAs cloned from the skin secretion of L. caerulea (EMBL accession Number AY218778-82). This approach was applied as the segment of the $5^{\prime}$-untranslated region employed was found to be highly conserved among the homologous peptide cDNAs [31]. An additional advantage of this strategy was that the entire open-reading frame of these transcripts could be deduced through a single $3^{\prime}$-RACE procedure. This PCR cycling procedure was carried out as follows: initial denaturation step: $60 \mathrm{~s}$ at $94^{\circ} \mathrm{C}$; 40 cycles of amplification: denaturing for $30 \mathrm{~s}$ at $94^{\circ} \mathrm{C}$; primer annealing for $30 \mathrm{~s}$ at $61^{\circ} \mathrm{C}$; and strand extension for $180 \mathrm{~s}$ at $72^{\circ} \mathrm{C}$. RACE-PCR products were analysed by DNA agarose gel electrophoresis, purified, and cloned in a pGEM $^{\circledR}$ - T Easy vector system (Promega Corporation, Southampton, UK), and the selected samples were sequenced by an ABI 3730 DNA automated analyser (Applied Biosystems, Foster City, CA, USA). The nucleic acid sequences were translated into amino acid sequences by the ExPASy Translate Tool online portal. The deduced preprocaeridins were analysed using the Blast Alignment Search Tool (BLAST) of the National Centre for Biotechnology Information (NCBI) by comparing to peptides with known amino acid sequences in the protein database. Alignments of similar regions were established by MEGA 6. The nucleotide sequences of the cDNA encoding the novel Caeridins were registered with the European Nucleotide Archive (ENA) browser at http://www.ebi.ac.uk/embl/ genomes/submission/.

4.3. Chromatographic Isolation and Primary Structural Characterisation of Novel cDNA-Deduced Caeridins from the Skin Secretion of L. caerulea. The lyophilised skin 
secretion of $L$. caerulea dissolved in solution A $\left(99.95 \% \mathrm{H}_{2} \mathrm{O}\right.$, $0.05 \%$ trifluoroacetic acid (TFA) was fractionated by reversed-phase HPLC using a Waters Binary pump HPLC system (Waters, Milford, MA, USA) fitted with an analytical column (Jupiter, C5, $300 \AA$, $5 \mu \mathrm{m}, 250 \mathrm{~mm} \times 4.6 \mathrm{~mm}$, Phenomenex, Macclesfield, Cheshire, UK) and eluted with a linear gradient formed from $100 \%$ solution A $\left(99.95 \% \mathrm{H}_{2} \mathrm{O}\right.$, $0.05 \% \mathrm{TFA})$ to $100 \%$ solution $\mathrm{B}(80.00 \%$ acetonitrile, $19.95 \% \mathrm{H}_{2} \mathrm{O}, 0.05 \% \mathrm{TFA}$ ) in $240 \mathrm{~min}$ at a flow rate of $1000 \mu \mathrm{l} / \mathrm{min}$. Fractions were collected at each minute, and the effluent was continuously detected at $\lambda=214 \mathrm{~nm}$. The dead volume between column and fraction collector was minimal $(20 \mu \mathrm{l})$.

The molecular masses of peptides in each fraction were analysed by matrix-assisted laser desorption/ionisation time-of-flight mass spectrometry (MALDI-TOF MS) on a linear time-of-flight Voyager DE mass spectrometer (Voyager DE, Perspective Biosystems, Foster City, CA, USA) in a positive detection mode using $\alpha$-cyano-4-hydroxycinnamic acid matrix to construct a mass spectral library of the $L$. caerulea skin secretion peptide. The instrument was calibrated in the range of $1-4 \mathrm{kDa}$, and the accuracy of mass determinations was $\pm 0.1 \%$. The computed molecular masses of predicted mature Caeridins deduced from encoded cDNA were used to interrogate the mass spectral library to identify the putative Caeridins. The skin secretion fractions containing the putative Caeridins diluted in solution A $\left(99.90 \% \mathrm{H}_{2}\right.$ $\mathrm{O}, 0.10 \%$ formic acid) were pumped directly onto an analytical HPLC column (Jupiter, C18, $300 \AA, 5 \mu \mathrm{m}, 150 \mathrm{~mm} \times$ $4.6 \mathrm{~mm}$, Phenomenex, Macclesfield, Cheshire, UK) connected to an LCQ Fleet ESI ion-trap mass spectrometer (Thermo Fisher, San Jose, CA, USA) and eluted from 100\% solution A $\left(99.90 \% \mathrm{H}_{2} \mathrm{O}, 0.10 \%\right.$ formic acid) to $100 \%$ solution $\mathrm{B}\left(19.90 \% \mathrm{H}_{2} \mathrm{O}, 80.00 \%\right.$ acetonitrile, and $0.10 \%$ formic acid) in $135 \mathrm{~min}$ at a flow rate of $20 \mu \mathrm{l} / \mathrm{min}$. Mass analysis was performed in a positive ion mode with acquired spectra in the range of $500-2000 \mathrm{~m} / z$ with $>50 \%$ relative intensity during HPLC-MS. Parameters for electrospray ionisation iontrap mass spectrometry (ESI/MS) were spray voltage $+4.5 \mathrm{kV}$, drying gas temperature $320^{\circ} \mathrm{C}$, drying gas flow $200 \mu \mathrm{l} / \mathrm{min}$, and maximum accumulation time (ion trap) $350 \mathrm{~ms}$. The first mass analysis was performed in full-scan mode, then peptide ions with $>50 \%$ relative intensity were selected for fragmentation by collision-induced dissociation (CID), to generate $b$ and $y$ ions detected in a second mass analysis. The instrument was controlled by Xcalibur software (Thermo Fisher, San Jose, CA, USA), and data analysis was performed using Proteome Discoverer 1.0 (Thermo Fisher, San Jose, CA, USA). Sequest ${ }^{\mathrm{TM}}$ algorithm was employed to compare the acquired fragment ion profiles with the theoretical fragment ions generated from a FASTA database specific for this species built by "shotgun" cloning (as described above) to confirm the amino acid sequences of individual Caeridins.

4.4. Solid-Phase Peptide Synthesis. The novel Caeridins, positive peptide Melittin, and negative peptide Bradykinin were synthesised by solid-phase Fmoc chemistry using a Tribute automated solid phase peptide synthesiser 4 (Protein Technologies, Tucson, AZ, USA). After cleavage from resin and deprotection, each crude peptide was obtained. The amino acid sequences of these peptides are summarised in Table 5 . The authenticity of the synthetic peptides was established by HPLC purification and confirmed by MALDI-TOF (Voyager DE, Perspective Biosystems, Foster City, CA, USA) and an LCQ Fleet electrospray ion-trap mass spectrometer (Thermo Fisher Scientific, San Francisco, CA, USA).

\subsection{Secondary Structural Determination by Circular} Dichroism (CD). CD spectra were obtained at $20^{\circ} \mathrm{C}$ using a $1 \mathrm{~mm}$ high-precision quartz cell (Hellma Analytics, Essex, UK) with a JASCO J-815 CD spectrometer (Jasco, Essex, UK). The measurement range was from $260 \mathrm{~nm}$ to $190 \mathrm{~nm}$ at a scanning speed of $200 \mathrm{~nm} / \mathrm{min}$. The bandwidth was $1 \mathrm{~nm}$, and the data pitch was $0.5 \mathrm{~nm}$. Caeridins were, respectively, dissolved in $10 \mathrm{mM} \mathrm{NH}_{4} \mathrm{Ac}$ or $10 \mathrm{mM} \mathrm{NH}_{4} \mathrm{~A}$ c with $50 \%$ TFE to reach a final concentration of $100 \mu \mathrm{M}$. The CD spectra were analysed by a K2D3 online portal programme [13].

4.6. Rat Smooth Muscle Tests. Female Wistar rats (250-300 g) were euthanized by $\mathrm{CO}_{2}$ asphyxiation followed by cervical dislocation under appropriate Home Office (UK) animal licenses. Full urinary bladder and ileum were carefully removed from the abdomen, then placed in cold Kreb's solution $\left(118 \mathrm{mM} \mathrm{NaCl}, 4.7 \mathrm{mM} \mathrm{KCl}, 25 \mathrm{mM} \mathrm{NaHCO}_{3}, 1.15 \mathrm{mM}\right.$ $\mathrm{NaH}_{2} \mathrm{PO}_{4}, 2.5 \mathrm{mM} \mathrm{CaCl}_{2}, 1.1 \mathrm{mM} \mathrm{MgCl}$, and $5.6 \mathrm{mM}$ glucose), equilibrated with a carbogen mixture $\left(95 \% \mathrm{O}_{2}, 5 \%\right.$ $\mathrm{CO}_{2}$ ) [32]. The prepared smooth muscles linked with transducers were placed in $2 \mathrm{ml}$ capacity organ baths with Kreb's solution flowing through at $2 \mathrm{ml} / \mathrm{min}$ and maintained at $37^{\circ} \mathrm{C}$ with constant bubbling of carbogen gas mixture (95\% $\mathrm{O}_{2}, 5 \% \mathrm{O}_{2}$ ) and equilibrated for $1 \mathrm{~h}$ prior to analysis. Then the viability of these smooth muscle preparations was tested by $60 \mathrm{mM} \mathrm{KCl}$. Caeridins were tested at sequential molar concentrations in the range from $10^{-6} \mathrm{M}$ to $10^{-11} \mathrm{M}$. Doseresponse curves were depicted for each Caeridin on individual smooth muscle preparations $(n=5)$. Changes in tension of the smooth muscle preparations were detected by pressure transducers connected to a PowerLab System (ADInstruments Pty Ltd.). Data were recorded and calculated to obtain the means of responses and standard error of means (SEM). The dose-response curve of each Caeridin was established using best-fit algorithms through the data analysis package provided by GraphPad Prism (Version 6.0; GraphPad Software Inc., San Diego, CA, USA), and the comparative $\mathrm{EC}_{50}$ value for each peptide was depicted.

4.7. Antimicrobial Tests. The antimicrobial activities were tested by the broth microdilution method and evaluated by the determination of MIC values against different tested microorganisms, the Gram-positive bacteria, S. aureus (NCTC 10788), E. faecalis (NCTC12697), and MRSA (NCTC 12493); the Gram-negative bacterium, E. coli (NCTC 10418); and the yeast, C. albicans (NCYC 1467). The microorganisms were cultured to their log phase in MHB and diluted to $5 \times 10^{5} \mathrm{CFU} / \mathrm{ml}$ then subsequently treated with peptide solutions of gradient concentrations. After incubation at $37^{\circ} \mathrm{C}$ overnight, the growth of microorganisms was 
TABle 5: The amino acid compositions of novel Caeridins, positive peptide melittin, and negative peptide bradykinin.

\begin{tabular}{lc}
\hline Peptide & Amino acid sequence \\
\hline Caeridin-1 & $\mathrm{H}_{2} \mathrm{~N}-$ GLLDGLLGTLGL-CONH \\
S5-Caeridin-1 & $\mathrm{N}_{2} \mathrm{H}$-GLLDSLLGGLGL-CONH \\
Caeridin-a1 & $\mathrm{H}_{2} \mathrm{~N}-$ GLFDIVGKLLGGLGL-CONH \\
& \\
Melittin & $\mathrm{H}_{2} \mathrm{~N}-$ GIGAVLKVLTTGLPALISWIKRKRQQ- \\
Bradykinin & $\mathrm{CONH}_{2}[15-17]$ \\
\hline
\end{tabular}

detected at a wavelength of $550 \mathrm{~nm}$ using a Synergy HT plate reader (Biolise BioTek ELx808, Winooski, VT, USA). The MICs were determined as the lowest concentration of peptide where growth was detectable.

4.8. Cell Membrane-Permeable Tests. The cell membrane permeability of S. aureus was tested with SYTOX Green Nucleic Acid Stain (Life Technologies, Carlsbad, CA, USA). The logphase $S$. aureus was pelleted and suspended in 5\% TSB in $0.85 \% \mathrm{NaCl}$ solution to achieve $1 \times 10^{8} \mathrm{CFU} / \mathrm{ml}$ cells which was then treated with peptide solutions at $37^{\circ} \mathrm{C}$ for $2 \mathrm{~h}$. The maximum membrane-compromised $S$. aureus was produced by $70 \%$ isopropanol treatment. Subsequently, cells were mixed with $5 \mu \mathrm{M}$ SYTOX Green stain and incubated in the dark for $10 \mathrm{~min}$. The fluorescence was measured in a $37^{\circ} \mathrm{C}$ Synergy HT plate reader (Biolise BioTek ELx808, Winooski, VT, USA) at excitation and emission wavelengths of $480 \mathrm{~nm}$ and $528 \mathrm{~nm}$, respectively. The membrane permeability was calculated as

$$
\text { Membrane permeability }(\%)=\frac{\left(F-F_{0}\right)}{\left(F_{1}-F_{0}\right)} \times 100 \% \text {, }
$$

where $F$ represents the processed fluorescence intensity with peptide treatments, $F_{0}$ represents the processed fluorescence intensity of untreated $S$. aureus, and $F_{1}$ represents the processed fluorescence intensity in the maximum membranecompromised S. aureus (70\% isopropanol-treated). The fluorescence intensities of background were subtracted prior to calculation.

The membrane permeabilsation of E.coli was determined by measuring the release of $\beta$-galactosidase activity from $E$. coli into the culture medium with ONPG as the substrate. The log-phase E. coli was grown in MHB medium containing $2 \%$ lactose at $37^{\circ} \mathrm{C}$, and the cells were pelleted. The cell pellets were suspended in $10 \mathrm{mM}$ PBS (pH 7.4) containing $1.5 \mathrm{mM}$ ONPG and diluted to $1 \times 10^{8} \mathrm{CFU} / \mathrm{ml}$. Aliquots of cells were incubated with different concentrations of peptides at $37^{\circ} \mathrm{C}$. Permeabilisation was measured at $420 \mathrm{~nm}$ every $2 \mathrm{~min}$ from 0 to $30 \mathrm{~min}$, which reflects ONPG influx into the cells working as an indicator of the permeability of the tested peptides.

The membrane permeabilisation of the human microvascular endothelial cell line, HMEC-1, was evaluated using the Pierce LDH Cytotoxicity Assay Kit (Thermo Fisher Scientific, San Francisco, CA, USA). HMEC-1 cells were cultured in MCDB-131 medium (Life Technology, Paisley, UK) with $10 \% \mathrm{FBS}, 10 \mathrm{ng} / \mathrm{ml}$ epidermal growth factor (EGF) (Life
Technology, Paisley, UK), 10 mM L-glutamine (Life Technology, Paisley, UK), and $1 \%$ penicillin-streptomycin (Sigma-Aldrich, St. Louise, MO, USA), at $37^{\circ} \mathrm{C}$ under $5 \%$ $\mathrm{CO}_{2}$. Cells were seeded in a 96-well plate at 5000 cells per well and cultured overnight to $80 \%$ confluency. Then, the cells were treated with different peptide solutions of gradient concentrations from $10^{-7} \mathrm{M}$ to $10^{-4} \mathrm{M}$ for $24 \mathrm{~h}$ at $37^{\circ} \mathrm{C}, 5 \% \mathrm{CO}_{2}$, and $\mathrm{H}_{2} \mathrm{O}$-treated cells were made as the spontaneous $\mathrm{LDH}$ release control. Lysis buffer was added to cells and incubated for $45 \mathrm{~min}$ at $37^{\circ} \mathrm{C}, 5 \% \mathrm{CO}_{2}$, to produce the lysis buffertreated cells which were referred to as maximum $\mathrm{LDH}$ release control. Then $50 \mu \mathrm{l}$ of each sample supernatant was transferred to a 96-well flat-bottom plate in triplicate wells, to which $50 \mu \mathrm{l}$ of reaction mixture was added, incubated, and protected from light at room temperature for $30 \mathrm{~min}$. After addition of $50 \mu \mathrm{l}$ Stop Solution to each sample well and removal of bubbles present in sample wells, the absorbance at $490 \mathrm{~nm}$ and $680 \mathrm{~nm}$ was measured. The absorbance values at $680 \mathrm{~nm}$ were subtracted from the absorbance values at $490 \mathrm{~nm}$ before calculation of the level of LDH release (cytotoxicity). The level of LDH release was calculated as

$$
\text { LDH release }(\%)=\frac{\left(L-L_{0}\right)}{\left(L_{1}-L_{0}\right)} \times 100 \% \text {, }
$$

where $L$ refers to sample-treated $\mathrm{LDH}$ activity, $L_{0}$ to spontaneous $\left(\mathrm{H}_{2} \mathrm{O}\right.$-treated) $\mathrm{LDH}$ activity, and $L_{1}$ to maximum (lysis buffer-treated) LDH activity.

Data analysis was performed using one-way analysis of variance followed by Dunnett's multiple comparison tests with maximum LDH release control in GraphPad Prism (Version 6.0; GraphPad Software Inc., San Diego, CA, USA).

4.9. Haemolytic Tests. The haemolysis of Caeridins was tested on prepared defrinated horse red blood cells (TCS Biosciences Ltd., Buckingham, UK) by incubating equal volumes of peptide solutions with erythrocyte suspensions at $37^{\circ} \mathrm{C}$ for $2 \mathrm{H}$. Maximum haemolysis control was included by incubating equal volumes of $1 \%$ Triton X-100 (Sigma-Aldrich, St. Louis, MO, USA) with erythrocyte suspensions. Lysis of erythrocytes was detected by the measurement of supernatant absorbance at a wavelength of $550 \mathrm{~nm}$ using a Synergy HT plate reader (Biolise BioTek ELx808, Winooski, VT, USA). The level of haemolysis was as calculated as

$$
\text { Haemolysis }(\%)=\frac{\left(A-A_{0}\right)}{\left(A_{1}-A_{0}\right)} \times 100 \% \text {, }
$$

where $A$ represents the absorbance with peptide treatments, $A_{0}$ represents the average absorbance in untreated erythrocytes, and $A_{1}$ represents the average absorbance in the maximum haemolysis control (1\% Triton X-100-treated).

\section{Conclusions}

The discovery of Caeridin-1, S5-Caeridin-1, and Caeridin-a1 not only contributed templates for drug design but also provided evidence that peptides from frog skin secretions possess bioactive properties and uphold expectations that 
peptides derived from natural resources may contribute to the clinical development of novel therapeutics.

\section{Abbreviations}

$\begin{array}{ll}\text { HPLC: } & \begin{array}{l}\text { High-performance liquid } \\ \text { chromatography }\end{array} \\ \text { MIC: } & \text { Minimum inhibitory concentration } \\ \text { MBC: } & \text { Minimum bactericidal concentration } \\ \text { CID: } & \text { Collision-induced dissociation } \\ \text { MALDI-TOF MS: } & \text { Matrix-assisted laser desorption/ionisa- } \\ & \text { tion time-of-flight mass spectrometry } \\ \text { ESI/MS: } & \begin{array}{l}\text { Electrospray ionisation ion-trap mass } \\ \text { spectrometry. }\end{array}\end{array}$

\section{Data Availability}

The data used to support the findings of this study are available from the corresponding author upon request.

\section{Disclosure}

An early progress of this work was presented in the Drug Discovery \& Therapy World Congress: https://www.ddtwc.com/ abstracts/Lei-Li.php.

\section{Conflicts of Interest}

The authors declare no conflict of interest.

\section{Authors' Contributions}

Tianbao Chen, Mei Zhou, Qing Wu, and Lei Wang conceived and designed the experiments; Lei Li, Xi Wang, and Huimin Lu performed the experiments; Lei Li and Lei Wang analysed the data; Lei Wang contributed reagents/materials/analysis tools; Lei Li wrote the paper; Chris J. Watson, Xinping Xi, and Mei Zhou revised the paper”.

\section{References}

[1] D. J. Craik, D. P. Fairlie, S. Liras, and D. Price, "The future of peptide-based drugs," Chemical Biology \& Drug Design, vol. 81, no. 1, pp. 136-147, 2013.

[2] S. Sachdeva, "Peptides as 'drugs': the journey so far," International Journal of Peptide Research and Therapeutics, vol. 23, no. 1, pp. 49-60, 2017.

[3] C. Lacombe, C. Cifuentes-Diaz, I. Dunia, M. Auber-Thomay, P. Nicolas, and M. Amiche, "Peptide secretion in the cutaneous glands of South American tree frog Phyllomedusa bicolor: an ultrastructural study," European Journal of Cell Biology, vol. 79, no. 9, pp. 631-641, 2000.

[4] B. T. Clarke, "The natural history of amphibian skin secretions, their normal functioning and potential medical applications," Biological Reviews, vol. 72, no. 3, pp. 365-379, 1997.

[5] R. C. Toledo and C. Jared, "Cutaneous granular glands and amphibian venoms," Comparative Biochemistry and Physiology Part A: Physiology, vol. 111, no. 1, pp. 1-29, 1995.

[6] E. König, O. R. P. Bininda-Emonds, and C. Shaw, "The diversity and evolution of anuran skin peptides," Peptides, vol. 63, pp. 96-117, 2015.
[7] P. C. Eterovick, A. C. O. de Queiroz Carnaval, D. M. BorgesNojosa, D. L. Silvano, M. V. Segalla, and I. Sazima, "Amphibian declines in Brazil: an overview," Biotropica, vol. 37, no. 2, pp. 166-179, 2005.

[8] J. W. Gibbon, D. E. Scott, T. J. Ryan et al., “The global decline of reptiles, déjà vu amphibians: reptile species are declining on a global scale. Six significant threats to reptile populations are habitat loss and degradation, introduced invasive species, environmental pollution, disease, unsustainable use, and global climate change," Bioscience, vol. 50, no. 8, pp. 653-666, 2000.

[9] R. J. Waugh, D. J. M. Stone, J. H. Bowie, J. C. Wallace, and M. J. Tyler, "Peptides from Australian frogs. Structures of the caeridins from Litoria caerulea," Journal of the Chemical Society, Perkin Transactions, vol. 1, no. 5, pp. 573-576, 1993.

[10] S. T. Steinborner, J. H. Bowie, M. J. Tyler, and J. C. Wallace, "An unusual combination of peptides from the skin glands of Ewing's tree frog, Litoria ewingi. Sequence determination and antimicrobial activity," Australian Journal of Chemistry, vol. 50, no. 9, pp. 889-894, 1997.

[11] H. De Loof, M. Rosseneu, R. Brasseur, and J.-M. Ruysschaert, "Functional differentiation of amphiphilic helices of the apolipoproteins by hydrophobic moment analysis," Biochimica et Biophysica Acta (BBA) - Protein Structure and Molecular Enzymology, vol. 911, no. 1, pp. 45-52, 1987.

[12] M. Zhou, T. Chen, B. Walker, and C. Shaw, "Novel frenatins from the skin of the Australasian giant white-lipped tree frog, Litoria infrafrenata: cloning of precursor cDNAs and identification in defensive skin secretion," Peptides, vol. 26, no. 12, pp. 2445-2451, 2005.

[13] C. Louis-Jeune, M. A. Andrade-Navarro, and C. Perez-Iratxeta, "Prediction of protein secondary structure from circular dichroism using theoretically derived spectra," Proteins: Structure, Function, and Bioinformatics, vol. 80, no. 2, pp. 374-381, 2012.

[14] R. GAUTIER, D. DOUGUET, B. ANTONNY, and G. Drin, "HELIQUEST: a web server to screen sequences with specific $\alpha$-helical properties," Bioinformatics, vol. 24, no. 18, pp. 21012102, 2008.

[15] E. Habermann, "Bee and wasp venoms," Science, vol. 177, no. 4046, pp. 314-322, 1972.

[16] E. Habermann, "Melittin-structure and activity," Natural Toxins, pp. 173-181, 1980.

[17] J. Chen and W. R. Lariviere, "The nociceptive and antinociceptive effects of bee venom injection and therapy: a double-edged sword," Progress in Neurobiology, vol. 92, no. 2, pp. 151-183, 2010.

[18] Anastasi, V. Erspamer, and G. Bertaccini, "Occurrence of bradykinin in the skin of Rana temperaria," Comparative Biochemistry and Physiology, vol. 14, no. 1, pp. 43-52, 1965.

[19] J. M. Conlon and U. Aronsson, "Multiple bradykinin-related peptides from the skin of the frog, Rana temporaria," Peptides, vol. 18 , no. 3, pp. 361-365, 1997.

[20] J. M. Conlon, "Bradykinin and its receptors in nonmammalian vertebrates," Regulatory Peptides, vol. 79, no. 2-3, pp. 71-81, 1999.

[21] P. Vlieghe, V. Lisowski, J. Martinez, and M. Khrestchatisky, "Synthetic therapeutic peptides: science and market," Drug Discovery Today, vol. 15, no. 1-2, pp. 40-56, 2010.

[22] L. F. Skerratt, L. Berger, R. Speare et al., "Spread of chytridiomycosis has caused the rapid global decline and extinction of frogs," EcoHealth, vol. 4, no. 2, pp. 125-134, 2007. 
[23] T. B. Hayes, P. Falso, S. Gallipeau, and M. Stice, "The cause of global amphibian declines: a developmental endocrinologist's perspective," Journal of Experimental Biology, vol. 213, no. 6, pp. 921-933, 2010.

[24] J. C. Z. Woinarski, A. A. Burbidge, and P. L. Harrison, "Ongoing unraveling of a continental fauna: decline and extinction of Australian mammals since European settlement," Proceedings of the National Academy of Sciences of the United States of America, vol. 112, no. 15, pp. 4531-4540, 2015.

[25] M. A. Apponyi, T. L. Pukala, C. S. Brinkworth et al., "Hostdefence peptides of Australian anurans: structure, mechanism of action and evolutionary significance," Peptides, vol. 25, no. 6, pp. 1035-1054, 2004.

[26] D. Vanhoye, F. Bruston, P. Nicolas, and M. Amiche, "Antimicrobial peptides from hylid and ranin frogs originated from a 150-million-year-old ancestral precursor with a conserved signal peptide but a hypermutable antimicrobial domain," European Journal of Biochemistry, vol. 270, no. 9, pp. 20682081, 2003.

[27] S. T. Steinborner, G. J. Currie, J. H. Bowie, J. C. Wallace, and M. J. Tyler, "New antibiotic caerin 1 peptides from the skin secretion of the Australian tree frog Litoria chloris. Comparison of the activities of the caerin 1 peptides from the genus Litoria," The Journal of Peptide Research, vol. 51, no. 2, pp. 121-126, 1998.

[28] A. Anastasi, V. Erspamer, and R. Exdean, "Isolation and amino acid sequence of caerulein, the active decapeptide of the skin of Hyla caerulea," Archives of Biochemistry and Biophysics, vol. 125, no. 1, pp. 57-68, 1968.

[29] H. Jenssen, P. Hamill, and R. E. W. Hancock, "Peptide antimicrobial agents," Clinical Microbiology Reviews, vol. 19, no. 3, pp. 491-511, 2006.

[30] M. J. Tyler, D. J. M. Stone, and J. H. Bowie, “A novel method for the release and collection of dermal, glandular secretions from the skin of frogs," Journal of Pharmacological and Toxicological Methods, vol. 28, no. 4, pp. 199-200, 1992.

[31] T. Chen, C. Scott, L. Tang, M. Zhou, and C. Shaw, "The structural organization of aurein precursor cDNAs from the skin secretion of the Australian green and golden bell frog, Litoria aurea," Regulatory Peptides, vol. 128, no. 1, pp. 75-83, 2005.

[32] Y. Wu, L. Wang, C. Lin et al., "Vasorelaxin: a novel arterial smooth muscle-relaxing eicosapeptide from the skin secretion of the Chinese piebald odorous frog (Odorrana schmackeri)," PLoS One, vol. 8, no. 2, article e55739, 2013. 


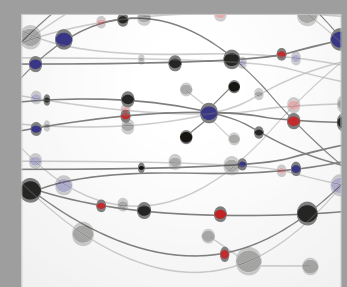

The Scientific World Journal
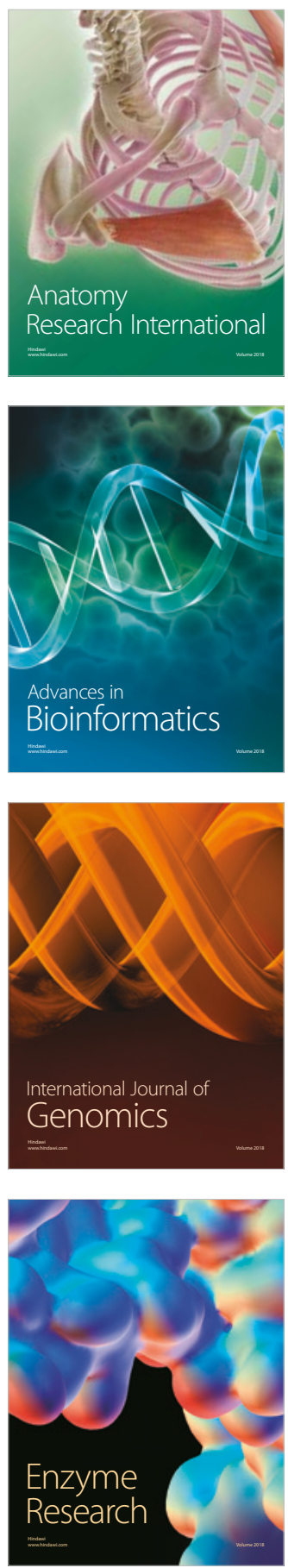
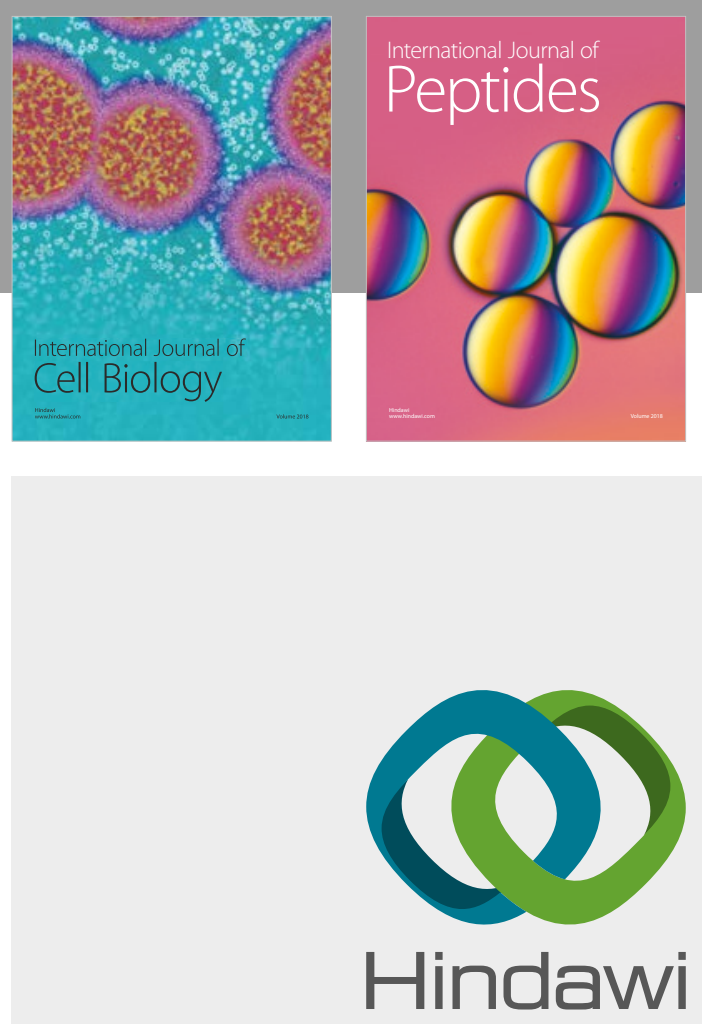

Submit your manuscripts at

www.hindawi.com
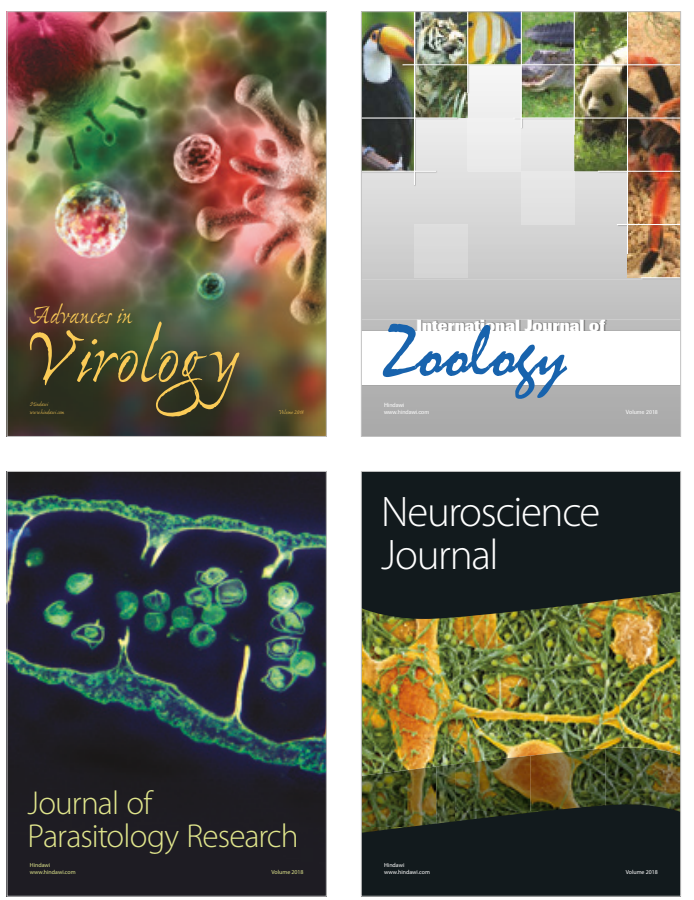
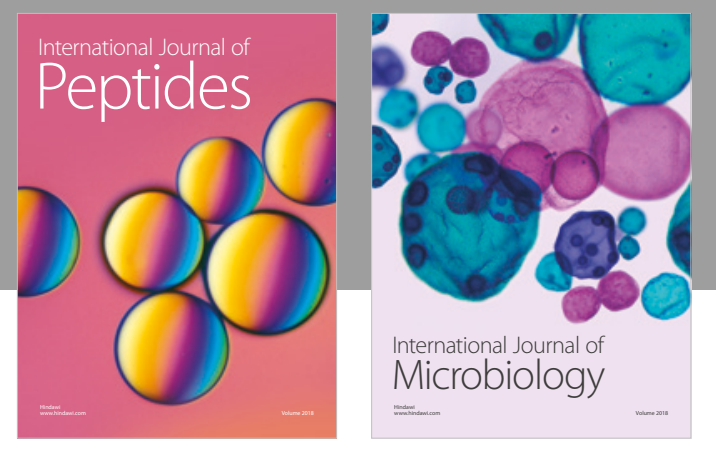

nternational Journal of Microbiology
Journal of
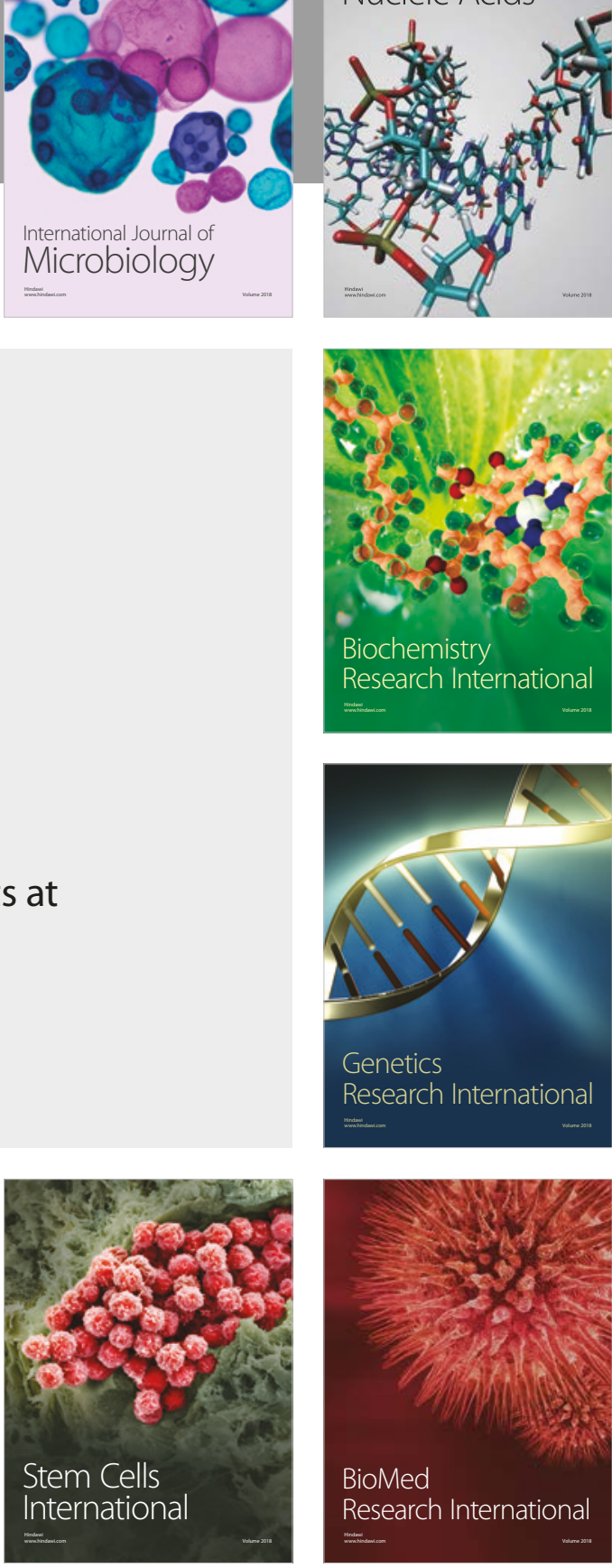
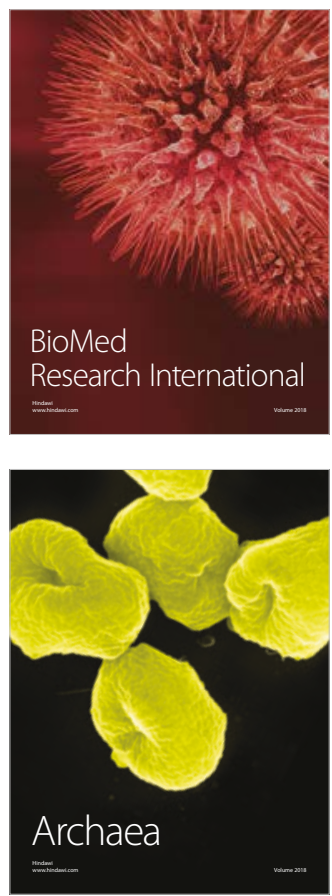